\title{
Ground Deformation Characteristics Induced by Mechanized Shield Twin Tunnelling along Curved Alignments
}

\author{
Dangzhong Wu, ${ }^{1}$ Kaiping Xu, ${ }^{2}$ Panpan Guo $\mathbb{D}^{3,4,5}$ Gang Lei, ${ }^{3,6}$ Kang Cheng, ${ }^{3,7}$ \\ and Xiaonan Gong ${ }^{3,4}$ \\ ${ }^{1}$ Zhejiang Zhongshui Engineering Technology Corporation Limited, Hangzhou 310000, China \\ ${ }^{2}$ Institute of Hydraulics and Estuary, Hangzhou 310000, China \\ ${ }^{3}$ Research Center of Coastal and Urban Geotechnical Engineering, Zhejiang University, Hangzhou 310058, China \\ ${ }^{4}$ Zhejiang Urban Underground Space Development Engineering Research Center, Zhejiang University, Hangzhou 310058, China \\ ${ }^{5}$ School of Civil Engineering, Hefei University of Technology, Hefei 230009, China \\ ${ }^{6}$ Beijing Urban Construction Design \& Development Group Company Limited, Beijing 100037, China \\ ${ }^{7}$ China Railway $11^{\text {th }}$ Bureau Group Co., Ltd., Wuhan 430061, China
}

Correspondence should be addressed to Panpan Guo; pp_guo@zju.edu.cn

Received 17 December 2020; Revised 9 January 2021; Accepted 22 January 2021; Published 8 February 2021

Academic Editor: Junhong Yuan

Copyright (c) 2021 Dangzhong Wu et al. This is an open access article distributed under the Creative Commons Attribution License, which permits unrestricted use, distribution, and reproduction in any medium, provided the original work is properly cited.

This paper investigates the ground deformation characteristics induced by mechanized shield twin tunnelling along curved alignments by adopting the nonlinear three-dimensional (3D) finite element method (FEM). The performance of the adopted FEM is demonstrated to be satisfactory by comparing the numerical analysis results with the field monitoring data in a typical case history and with the predicted results generated by a modified version of the Peck's empirical Gaussian formula. It has been found that the tunnelling-induced transverse ground surface settlement troughs and the distributions of the subsurface horizontal and vertical ground displacements are mostly similar in both form and magnitude for the considered various radii of curvature of tunnel alignment including $50 \mathrm{~m}, 100 \mathrm{~m}, 150 \mathrm{~m}, 200 \mathrm{~m}, 250 \mathrm{~m}, 300 \mathrm{~m}, 400 \mathrm{~m}$, and infinity (i.e., straight-line tunnel). Considering the variational characteristics of the ground deformations with the magnitude of the radius of curvature, the radius of curvature of $100 \mathrm{~m}$ can be regarded as a critical tunnel alignment radius of curvature controlling the transformation of the curved tunnellinginduced ground deformational behaviors. For the benefit of geotechnical engineers interested in curved tunnelling with a small radius of curvature, a discussion of the technologies for reducing the overexcavation and improving the accuracy of tunnel lining segment installation is also presented.

\section{Introduction}

Tunnels play an important part in the development of economics and society, and they have many uses such as transportation, including canals, trains, metros, road vehicles, etc., for mining ores, and for conducting sewage and water [1-3]. It has been estimated that the length of the tunnels constructed annually since 2013 reaches approximately $5200 \mathrm{~km}$, and that the current tunnelling market represents $6-7 \%$ of the global infrastructure construction market. Therefore, tunnelling has always been a significant focus of research in the area of civil engineering [4-6].
Depending on the considerations of various factors such as geological conditions, environmental impacts, construction cost and period, and tunnel dimensions, a tunnel may be excavated using one of the commonly adopted methods including mainly the cut-and-cover method [7, 8], drill-and-blast method $[9,10]$, mechanized shield tunnelling method using a tunnel boring machine (TBM) $[11,12]$, new Austrian tunnelling method [13, 14], and jacked box tunnelling method $[15,16]$. Among these methods, the mechanized shield tunnelling method has been widely used for constructing metros in many urban areas in the world [17-19]. This is because this method has several advantages 
over the other methods. The advantages are, for example, reduced environmental impacts in relation to noise, dust, ground surface settlement, vibrations, and disturbance to surrounding infrastructure; reduced labor cost and risk to the life of workers; enhanced tunnelling rate, especially in soft soils; and high automation construction level [20-24].

The construction procedure for mechanized shield tunnelling method includes four repeated steps: TBM advancement by thrust of hydraulic jacks, soil excavation by cutterhead, ring segment installation, and synchronous tail void grouting. These steps involve a complex interaction between TBM and the surrounding soil, which controls the behavior of the tunnel structure as well as the impact of the tunnelling process on the surrounding ground and facilities. To address this issue, a substantial amount of studies has been made. Two-dimensional (2D) finite-element (FE) models were established in the early days to estimate the ground movements induced by shield tunnelling [25-28]. Despite the simplicity and convenience in application of the 2D FE models, they have neglected the three-dimensional (3D) nature of tunnelling-soil interaction. For a more realistic simulation, fully 3D FE and finite-difference (FD) models were then developed to investigate the tunnel behavior and the tunnelling effects on the surrounding ground and infrastructure [29-37].

Despite the fact that an abundance of 3D FE or FD analysis has been made to investigate the behavior or influence of mechanized shield tunnelling, most of them only focus on mechanized shield tunnelling along straight alignments. The mechanism of the behavior of mechanized shield tunnelling along curved alignments as well as its effect on ground deformations and performance of adjacent existing structures are not well understood due to the limited investigations. By virtue of $3 \mathrm{D} \mathrm{FE}$ analysis and real-time monitoring in the field, Xie and Tang [38] investigated the effect of curved shield tunnelling on the additional settlement of an existing electric cable tunnel. It was found that curved tunnel construction could cause adverse effects on the existing tunnel. Li et al. [29] performed numerical simulations and on-site monitoring to investigate the interaction between a curved shield tunnelling and a straightline shield tunnelling. Zhang et al. [39] reported an in-depth numerical analysis of the whole shield tunnelling process along a curved trajectory. They concluded that the ground surface settlement induced by curved shield tunnelling is greater than that induced by straight-line shield tunnelling, due to the overcutting and yaw excavation loadings. By using 3D FEM, Sugimoto et al. [40] simulated the shield tunnelling behavior along a curved alignment in a multilayered ground. They pointed out that the ground movement at the excavated surface has a major role in the surrounding ground displacements during shield tunnelling.

The existing studies on the shield tunnelling behavior along curved alignment have not captured the effect of the magnitude of the curvature radius on the ground movements induced by curved shield tunnelling. A good understanding of this effect is indispensable for optimizing the alignment of a curved shield tunnel when the response of the adjacent structures to the tunnelling-induced ground movements needs to be strictly controlled. Moreover, shield twin tunnelling along curved alignments is booming in practice with the rapid urbanization. However, the characteristics of ground movements induced by shield twin tunnelling along curved alignments have not been thoroughly investigated so far. In addition, a summary of the critical construction technology for ensuring safety and stability during curved shield tunnelling is not available in the literature, which may hinder the development of the related technologies and even urbanization, especially in less-developed countries or regions.

In this paper, the effects of the magnitude of the tunnel alignment curvature radius on the characteristics of ground movements induced by mechanized shield twin tunnelling along curved alignments are systematically investigated through nonlinear 3D FEM. A typical case history with observed ground surface settlements induced by shield twin tunnelling along curved alignments is presented to validate the nonlinear 3D FEM. The ability of the empirical equations proposed by Peck in predicting the tunnelling-induced ground surface settlements is examined for the considered cases. In addition, a discussion of the critical stability guarantee technique is presented to provide reference for geotechnical engineering practitioners.

\section{Case History}

2.1. Engineering Overview. The considered case history in this study is a part of the shield twin tunnelling project for the construction of Hefei Metro Line 3 between the Qimen Road Station and the Grand Theater Station. A map for the location of the considered case history is shown in Figure 1. The dimensions for the area of research as depicted in Figure 1 are $100 \mathrm{~m} \times 60 \mathrm{~m}$. The tunnels with an internal diameter of $6 \mathrm{~m}$ are excavated by two earth pressure balance (EPB) shield machines. The EPB shield machine in the left tunnel is behind the EPB shield machine in the right tunnel with a lagging distance of $36 \mathrm{~m}$. From Figure 1, it can be found that the alignments of the shield twin tunnels are curved between the two stations mentioned above, especially for the area of research in this study. The objective of designing a curved alignment of shield tunnel in this case is to reduce as much as possible the adverse effects that the Swan Lake may produce on the construction and operation of the Hefei Metro Line 3. The radius of curvature for the alignments of the shield twin tunnels is $300 \mathrm{~m}$. The cover depth of the shield twin tunnels is approximately $7.9 \mathrm{~m}$. Considering the small magnitudes of the radius of curvature and the cover depth, the ground deformations induced by shield twin tunnels need to be estimated accurately for the protection of the structures adjacent to the considered case history.

2.2. Geological Conditions. Figure 2 shows an elevation view of the soil layers on the site of the considered case history. It is indicated that the ground consists of four soil layers, which can be categorized, according to the Chinese standard for engineering classification of soil, as, respectively, plain fill, 


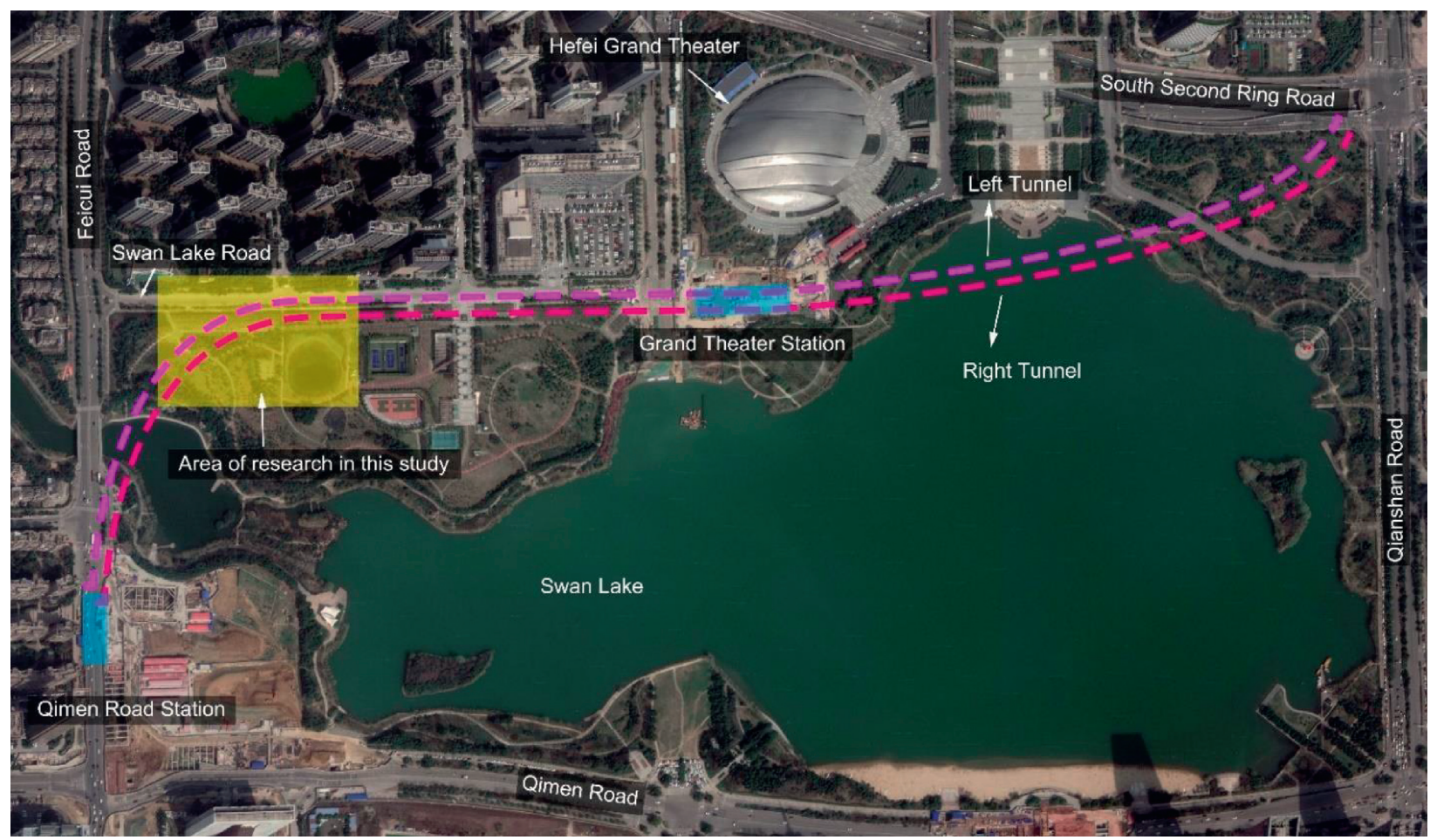

FIGURE 1: A map for the location of the considered case history.

Ground surface

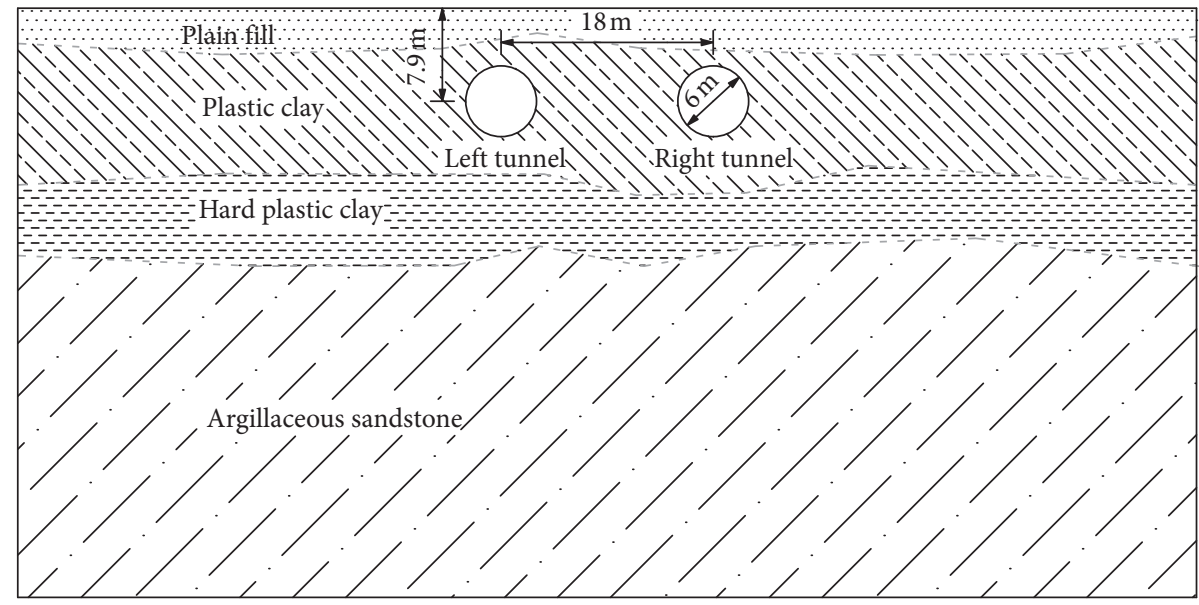

FIgURE 2: Elevation view of the soil layers.

plastic clay, hard plastic clay, and argillaceous sandstone from ground surface to a depth of $50 \mathrm{~m}$ below ground surface. The average thickness is approximately $3 \mathrm{~m}$ for the plain fill layer, $12 \mathrm{~m}$ for the plastic layer, and $6 \mathrm{~m}$ for the hard plastic clay layer. The type of groundwater is dominated by perched groundwater, which is mainly within the plain fill layer. The cover depth of the groundwater table ranges between $1.7 \mathrm{~m}$ and $4.6 \mathrm{~m}$. Note that the average thickness for the argillaceous sandstone layer is greater than $29 \mathrm{~m}$, and only a fraction of the entire argillaceous sandstone layer is illustrated in Figure 2. A summary of the basic physical and mechanical parameters for these soil layers on the site of the considered case history is presented in Table 1. These parameters, obtained by performing geotechnical tests in the field and laboratory, represent the average properties from the top to the bottom of a soil layer. In addition, it can be seen from Figure 2 that the tunnels are within the plastic clay layer.

2.3. Monitoring Arrangements. The ground surface settlements induced by the twin shield tunnelling along curved alignments are monitored using electronic levels and indium steel rulers during construction. The monitored data is useful for the control of the tunnelling process and for the manipulation of countermeasures aimed at protecting the 
TABLE 1: Basic parameters of the soil on the site of the considered case history.

\begin{tabular}{lcccccccccc}
\hline Soil & $\gamma$ & $c$ & $\varphi$ & $E_{s}$ & $v$ & $K_{0}$ & $k_{h}$ & $k_{v}$ & $K$ & $f_{a k}$ \\
\hline Plain fill & 19.6 & 53 & 13.0 & 6.2 & 0.25 & 0.48 & 10.1 & 8.5 & 0.39 & 182.9 \\
Plastic clay & 19.1 & 64 & 13.5 & 8.5 & 0.27 & 0.39 & 40.8 & 35.3 & 0.01 & 221.7 \\
Hard plastic clay & 20.2 & 40 & 13.7 & 10.6 & 0.31 & 0.43 & 68.5 & 79.1 & 0.02 & 250.5 \\
Argillaceous sandstone & 23.4 & 95 & 26.0 & 20.1 & 0.29 & 0.28 & 60.6 & 67.8 & 0.10 & 302.4 \\
\hline
\end{tabular}

$\gamma=$ unit weight $\left(\mathrm{kN} / \mathrm{m}^{3}\right) ; c, \varphi=$ cohesion $(\mathrm{kPa})$ and angle of internal friction $\left({ }^{\circ}\right)$ by direct shear tests, respectively; $E_{s}=$ modulus of compressibility $(\mathrm{MPa})$; $\nu=$ Poisson's ratio; $K_{0}=$ coefficient of earth pressure at rest; $k_{h}, k_{v}=$ horizontal and vertical coefficients of subgrade reaction, respectively; $K=$ coefficient of permeability; and $f_{a k}=$ load bearing capacity $(\mathrm{kPa})$.

adjacent infrastructures. A schematic diagram of the distribution of the monitoring points is presented in Figure 3(a). The distance between two monitoring points is $3 \mathrm{~m}$ for the monitoring points directly above the tunnels, and this value is increased gradually to be $8 \mathrm{~m}$ when moving transversely away from the tunnels. An illustration and a photograph for the marker of a monitoring point are presented, respectively, in Figure 3(b) and 3(c). The marker is installed in four steps. First, drill a hole in the ground to the depth of the undisturbed soil layer using a core drilling rig. Second, insert a screw-thread steel with a round head of $16 \mathrm{~mm}$ in diameter and $0.8 \mathrm{~m}$ in length into the undisturbed soil layer below the bottom of the drilled hole in the first step. Third, fill in the drilled hole with standard sand. Finally, install a protective cap on the top of the drilled hole. In addition, the perpendicularity of the screw-thread steel marker is ensured by using a brass plumb bob during the installation process.

\section{Numerical Modelling}

3.1. Finite Element Code. A finite element (FE) code, namely, midas GTS NX (New eXperience of Geo-Technical analysis System), is adopted in this study for simulating the ground deformation characteristics induced by shield twin tunnelling along curved alignments with different radii of curvature. This FE code has been applied successfully in solving many geotechnical problems such as slope stability [41], soil-structure interactions [42-44], excavations [45-48], tunnelling [49], and fluid-mechanical interactions [50].

3.2. Meshing and Boundary Conditions. The meshing of the entire finite element model is presented in Figure 4. It is shown that the overall dimensions of the meshed finite element model are $100 \mathrm{~m}$ in the $X$-axis direction, $60 \mathrm{~m}$ in the $Y$-axis direction, and $50 \mathrm{~m}$ in the $Z$-axis direction. These dimensions are sufficient for minimizing the boundary effect according to a preliminary analysis. To balance the accuracy of the computed results and the duration required for completing the analysis, the mesh is dense in the area of tunnels and becomes coarser with increasing the distance from the tunnels. As illustrated in Figure 4, roller supports are applied to the vertical boundaries of the finite element model to restrain the displacements normal to the boundary. The displacements of the bottom boundary are restrained in all directions by virtue of pin supports. The top boundary of the model is left free to displace and rotate. A comparison of the meshing of the curved shield twin tunnels with different radius of curvature (ROC) is made in Figure 5. It is shown that eight different magnitudes of radius of curvature (i.e., $50 \mathrm{~m}, 100 \mathrm{~m}, 150 \mathrm{~m}, 200 \mathrm{~m}, 250 \mathrm{~m}, 300 \mathrm{~m}, 400 \mathrm{~m}$, and infinity) are considered in this study with the aim of investigating the effect of the magnitude of this parameter on the ground deformation characteristics induced by curved shield twin tunnels. The reason for the selection of these magnitudes of radius of curvature is that they are commonly adopted in engineering practice. In order to maintain as far as possible the smoothing of the tunnel alignment at a relatively small radius of curvature (e.g., $50 \mathrm{~m}$ ), the dimension of the meshing for the tunnels is determined to be $0.5 \mathrm{~m}$.

3.3. Constitutive Models and Parameters. In the numerical analysis, linear elastic model is adopted to describe the stress-strain behaviors of the grout, tunnel lining segment, and TBM shell, while the constitutive behavior of the soil is simulated with the Modified Mohr-Coulomb (MMC) model. The MMC model is an elastoplastic soil constitutive model evolved from the conventional Mohr-Coulomb (MC) model. Compared to the conventional MC model, the MMC model has the advantages of capturing the nonlinearity of the soil elastic behavior and the difference between the moduli of elasticity during loading and unloading. Moreover, this model is capable of simulating the shear hardening effect. Thanks to these advantages, the numerical analysis results are generally satisfactory when the soil behavior in excavation and tunnelling problems is simulated with the MMC model. In addition, in the MMC model, shear failure is independent of compression failure, and the yield function for this model can be expressed as

$$
\begin{aligned}
& f_{1}=\frac{q}{R_{1}(\theta)}-\frac{6 \sin \phi}{3-\sin \phi}(p+\Delta p)=0, \\
& f_{2}=\alpha\left(\frac{q}{R_{2}(\theta)}\right)^{2}+(p+\Delta p)^{2}-p_{c}^{2}=0,
\end{aligned}
$$

where $f_{1}=$ shear yield function, $f_{2}=$ compression yield function, $p=$ mean stress, $q=$ deviatoric stress, $\Delta p=$ mean stress increment, $p_{c}=$ preconsolidation pressure, $\phi=$ angle of internal friction, $R_{1}(\theta)=$ function associated with shear hardening, $R_{2}(\theta)=$ function associated with the shape of compression cap, $\theta=$ Lode's angle, and $\alpha=$ coefficient associated with the angle of internal friction of soil $\varphi$ (i.e., $\alpha=((3+\sin \varphi) /(3-\sin \varphi)))$. 

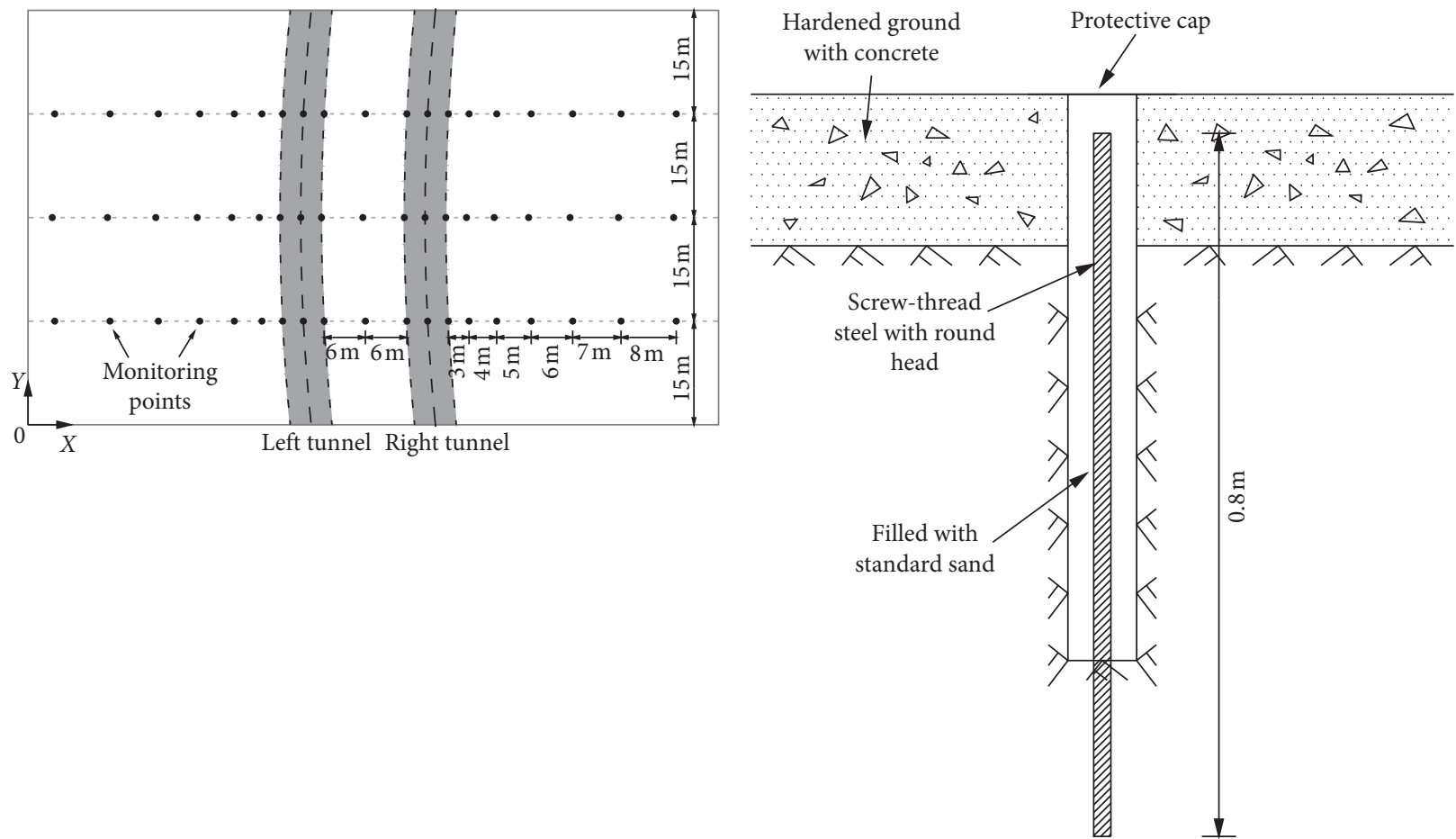

(a)

(b)

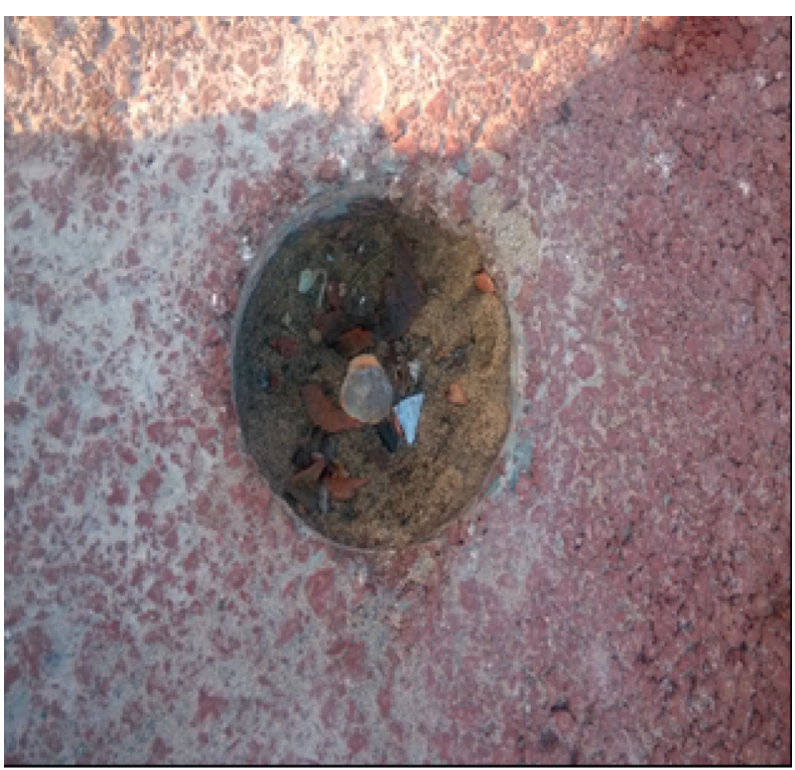

(c)

FiguRE 3: Schematic diagrams of ground surface settlement monitoring points: (a) distribution, (b) marker components, and (c) marker photograph.

The nonlinear parameters required for the MMC model include the secant stiffness by consolidated drained triaxial compression tests $E_{50}^{\text {ref }}$, tangent stiffness by oedometer tests $E_{\text {oed }}^{\text {ref }}$, unloading/reloading modulus of elasticity $E_{\text {ur }}^{\text {ref }}$, failure ratio $R_{f}$, reference pressure $p_{\text {ref }}$, stress-dependent power exponent $m$, void rate $e$, angle of internal friction at shear failure $\varphi_{\text {ult }}$, coefficient of lateral earth pressure for normal consolidated soil $K_{\mathrm{NC}}$, ultimate dilation angle $\delta_{\text {ult }}$, and cohesion $c$. The magnitudes of the parameters mentioned above can be derived from Table 1 or from experience. The parameters required for the linear elastic model are modulus of elasticity, Poisson's ratio, and unit weight. The magnitudes of the unit weight are, respectively, 21, 25, and $78.5 \mathrm{kN} /$ $\mathrm{m}^{3}$ for the grout, tunnel lining segment, and TBM shell. The 


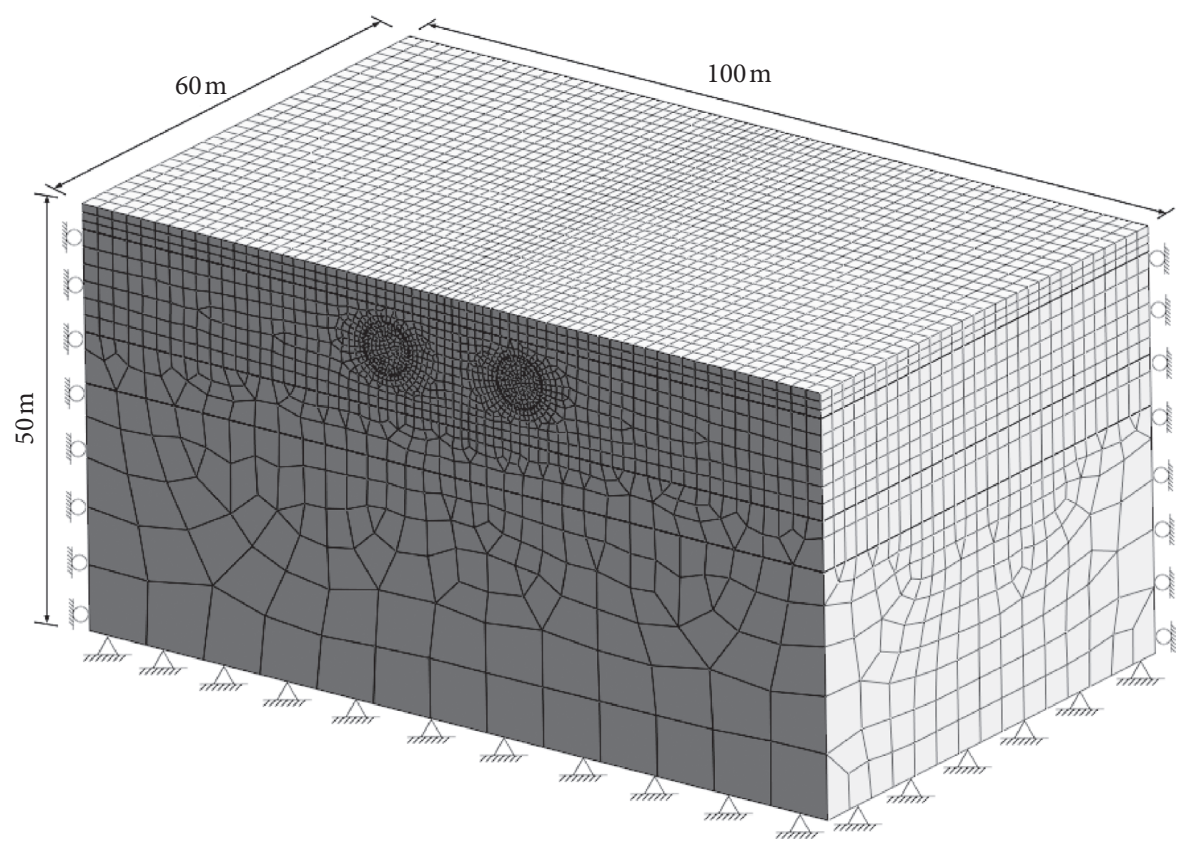

Figure 4: Meshing of the entire finite element model.

magnitudes of the Poisson's ratio are, respectively, 0.2, 0.27, and 0.2. The magnitudes of the modulus of elasticity are, respectively, $30 \mathrm{MPa}, 20 \mathrm{GPa}$, and $200 \mathrm{GPa}$.

3.4. Tunnelling Sequence Simulation. A step-by-step procedure is used to simulate the tunnelling process. A tunnelling step corresponds to a distance of excavation of $3 \mathrm{~m}$, which represents two times the width of a ring of tunnel lining segment. During a tunnelling step, the simulation involves activation of elements, construction loads, and boundary condition, and deactivation of elements and construction loads. The activated elements include the two-dimensional (2D) plate elements for a TBM shell of $3 \mathrm{~m}$ in length in the present step [see Figure 6(a)], the 2D plate elements for tunnel lining segments of $3 \mathrm{~m}$ in width in the former step [see Figure 6(b)], and the solid elements for grout layer of $3 \mathrm{~m}$ in length in the former step [see Figure 6(c)]. The activated construction loads include the tunnel face pressure of $120 \mathrm{kPa}$ in magnitude applied on the starting face of the soil elements to be excavated in the next step [see Figure 6(d)], the Jack thrust of $100 \mathrm{kPa}$ in magnitude applied on the ending face of the tunnel lining segment elements in the former step [see Figure 6(e)], and the grouting pressure of $150 \mathrm{kPa}$ in magnitude on the external surface of the tunnel lining segment elements in the former step [see Figure 6(f)]. As the magnitudes of the applied tunnel face pressure, the Jack thrust, and the grouting pressure in the numerical analysis are the same as that adopted in the considered case history, the appropriateness of the magnitudes of these parameters can be guaranteed. The activated boundary condition is the transformation of the mechanical properties of the grout layer elements from that corresponding to soil material to that corresponding to real grout material. The deactivated elements include the solid elements for soil to be excavated of $3 \mathrm{~m}$ in distance in the present step and the 2D plate elements for TBM shell of $3 \mathrm{~m}$ in length in the former step. The deactivated construction loads include the Jack thrust of $100 \mathrm{kPa}$ in magnitude applied on the ending face of the tunnel lining segment elements in the $(k-2)$ th step where $k$ represents the present step, the tunnel face pressure of $120 \mathrm{kPa}$ in magnitude applied on the starting face of the soil elements to be excavated in the present step, and the grouting pressure of $150 \mathrm{kPa}$ in magnitude on the external surface of the tunnel lining segment elements in the $(k-$ 2 )th step where $k$ represents the present step. Repeat the activation and deactivation manipulations described above until the completion of the excavation of the twin shield tunnels.

\section{Results and Discussion}

4.1. Empirical Formula for Predicting Ground Surface Settlements. An empirical formula for predicting the ground surface settlements induced by tunnelling was proposed by Peck (1969) [51] based on curve-fitting of an enormous amount of field monitoring results. The basic assumption of Peck's formula is that the transverse ground settlement profile induced by single tunnelling can be described with a Gaussian distribution function:

$$
\begin{aligned}
& S(x)=S_{\max } \exp \left(\frac{-x^{2}}{2 i^{2}}\right), \\
& S_{\max }=\frac{V_{L}}{i \sqrt{2 \pi}},
\end{aligned}
$$

where $x$ horizontal distance from tunnel axis, $S(x)=$ ground surface settlement at $x, S_{\max }=$ maximum ground surface settlement, $V_{L}=$ ground loss, and 


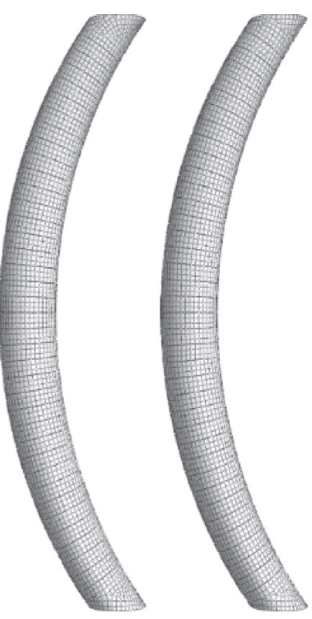

(a)

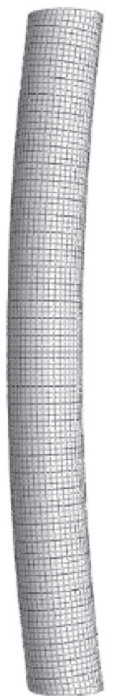

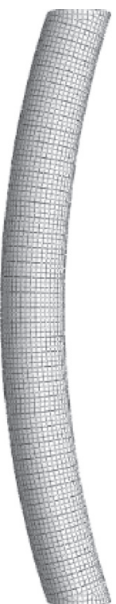

(b)

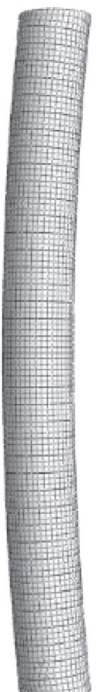

(e)
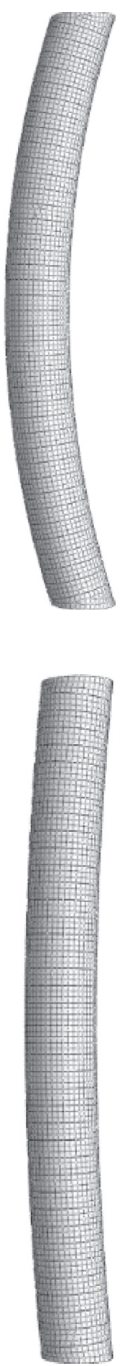

(f)

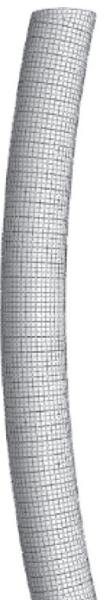

(c)

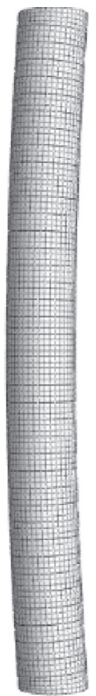

$(\mathrm{g})$
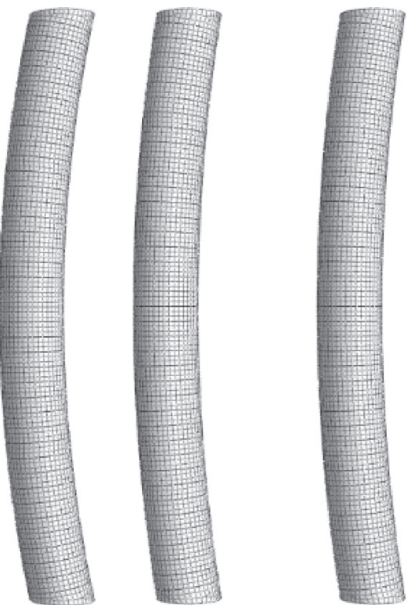

(d)
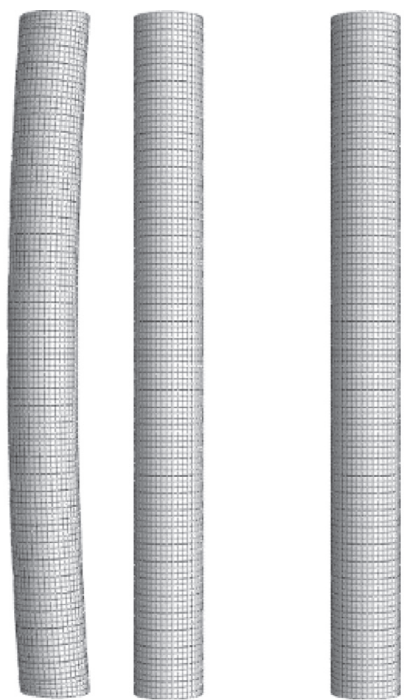

(h)

FIGURE 5: Meshing of the curved shield twin tunnels with a radius of curvature of: (a) $50 \mathrm{~m}$, (b) $100 \mathrm{~m}$, (c) $150 \mathrm{~m}$, (d) $200 \mathrm{~m}$, (e) $250 \mathrm{~m}$, (f) $300 \mathrm{~m}$, (g) $400 \mathrm{~m}$, and (h) infinity.

$i=$ settlement trough width [see Figure 7(a)]. Note that the maximum ground surface settlement is achieved at the tunnel axis, as depicted in Figure 7(a).

Prediction of tunnelling-induced ground surface settlements using equations (3) and (4) requires the assessment of ground loss and settlement trough width. In the literature, the ground loss is often assessed using empirical observations, taking no account of the effects of some critical factors such as soil type, tunnelling method, tunnel configuration, groundwater condition, and construction management quality [52-54]. Moreover, the ground loss should be carefully controlled during tunnelling $[55,56]$. The available equations for calculating the settlement trough width in the literature fall into four categories as summarized in Table 2. Note that in Table 2 the equation proposed by Knothe (1957) [57] is applicable only to rock-like materials of which the tensile strength differs greatly from other types of soil. In the present research work, the equation, $i=0.5 z_{0}$, proposed by
Rankin (1988) [61], is used to predict tunnelling-induced ground movements.

The Peck formula, as a convenient method of predicting tunnelling-induced ground movements, was proposed for the case of single tunnelling. For the twin tunnelling case, however, the use of the Peck formula is also feasible if a slight modification of the initial version of the Peck formula is made. Modification of the Peck formula made in the present research work is based on the superposition principle. In this case, the superposition principle is applicable as the ground movements induced by the left tunnel is independent of that by the right tunnel. The applicability of the superposition principle in estimating the ground surface movements has been demonstrated by Chen et al. (2012) [63] who reported a good agreement between the transverse ground surface settlement profiles obtained by finite element analysis and Peck's empirical equation. The modified version of the Peck formula is expressed as the following: 


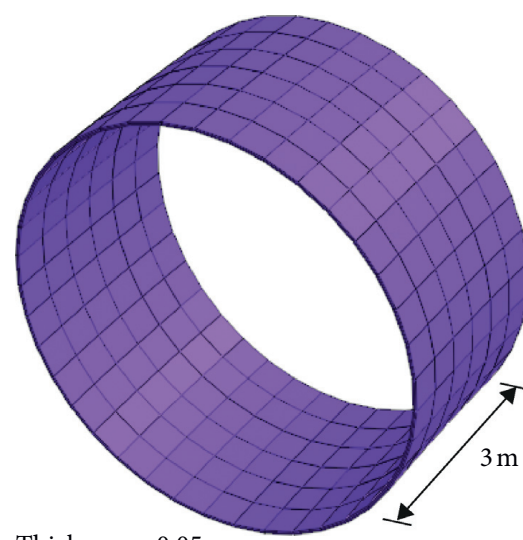

(a)

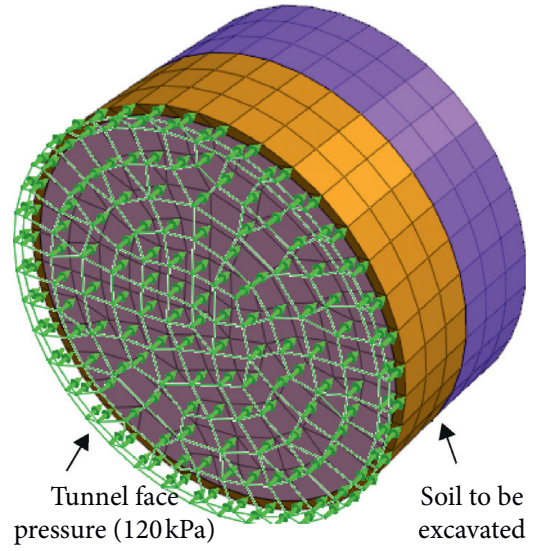

(d)

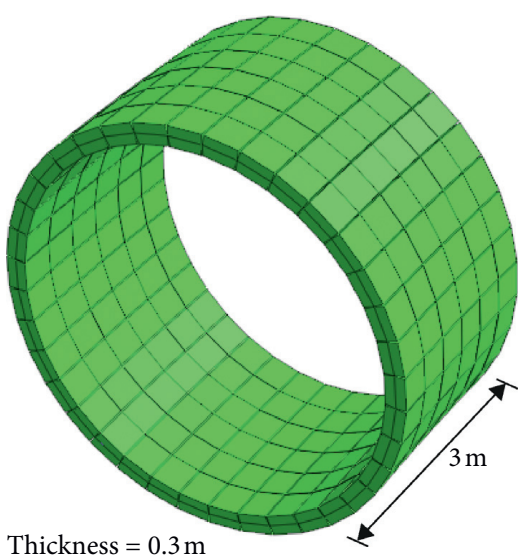

(b)

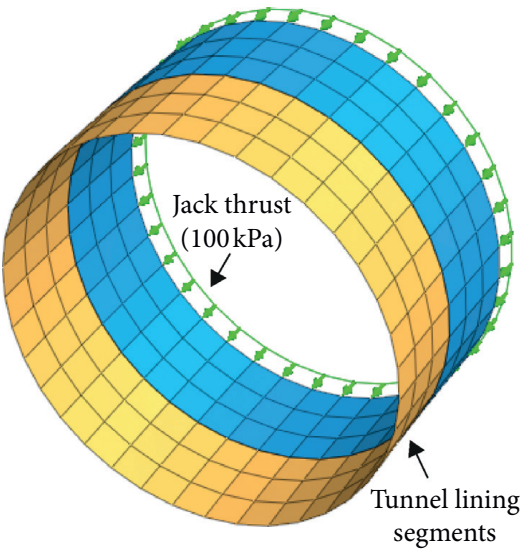

(e)

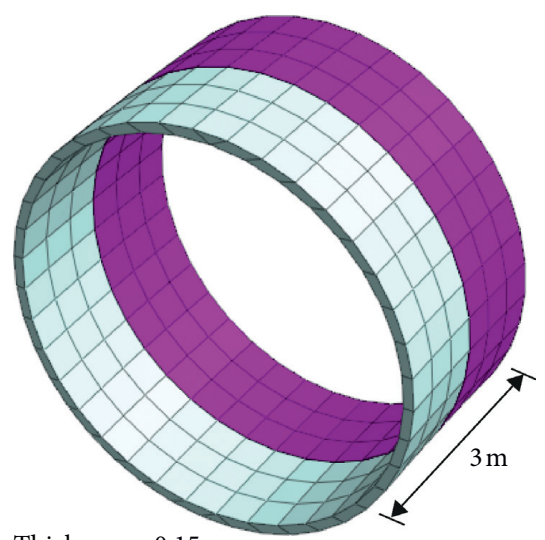

(c)

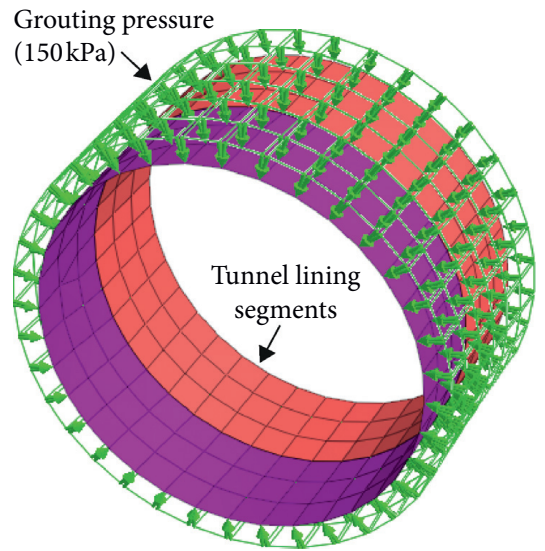

(f)

Figure 6: Tunnelling sequence simulation in a tunnelling step: (a) TBM shell, (b) tunnel lining segments, (c) grout layer, (d) tunnel face pressure, (e) Jack thrust, and (f) grouting pressure.

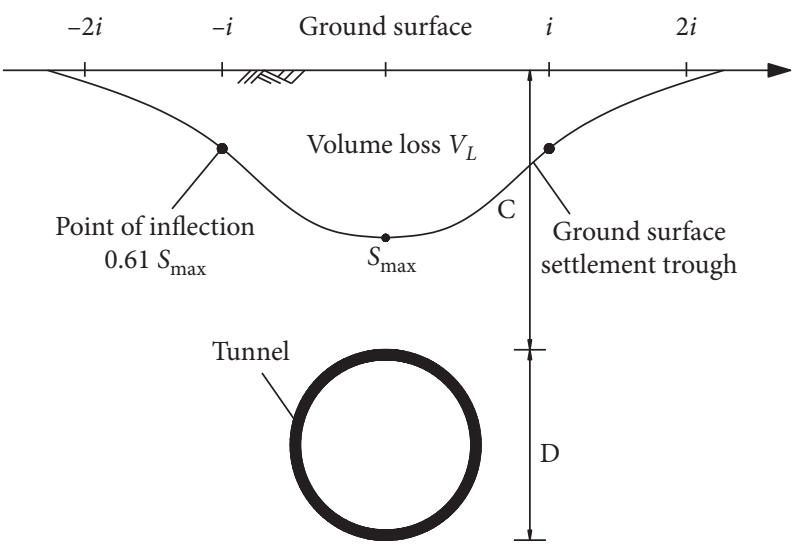

(a)

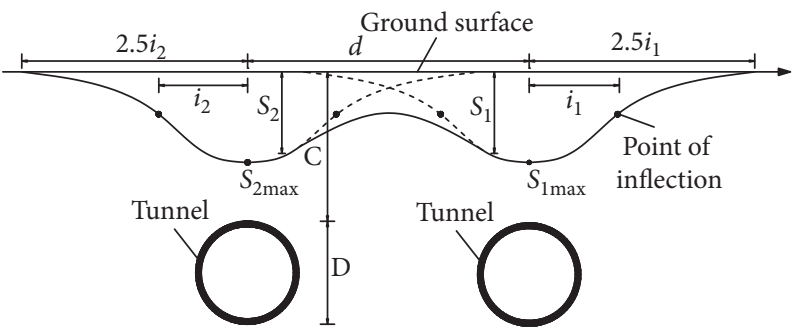

(b)

FIGURE 7: Schematic diagrams of transverse settlement profile induced by: (a) single tunnelling and (b) twin tunnelling. 
TABLE 2: Summary of equations for calculating settlement trough width.

\begin{tabular}{lcc}
\hline Equation & Application scope & Reference \\
\hline$i=z_{0} /(\sqrt{2 \pi} \tan (\pi / 4-t \varphi / 2))$ & Rock-like materials & [57] \\
$i=a R\left(z_{0} /(2 R)\right)^{n}$ & Various types of soil & [51, 52, 58, 59] \\
$i=a\left(b z_{0}+c R\right)$ & Loose sand or compacted clay & [60] \\
$i=a z_{0}+b$ & Cohesive soil or granular soil & [61, 62] \\
\hline
\end{tabular}

$z_{0}=$ tunnel's cover depth, $\varphi=$ soil's internal friction angle, $R=$ tunnel's radius, and $a, b, c, n=$ empirical coefficients.

$$
S(x)=\frac{V_{L}}{i \sqrt{2 \pi}}\left(\exp \left(\frac{-(x+0.5 d)^{2}}{2 i^{2}}\right)+\exp \left(\frac{-(x-0.5 d)^{2}}{2 i^{2}}\right)\right)
$$

where $d=$ horizontal distance between the two tunnel axes (see Figure 7(b)).

4.2. Ground Surface Settlements. A comparison of the final ground surface settlement troughs induced by curved twin tunnelling of $300 \mathrm{~m}$ in radius of curvature is made in Figure 8 between results by the finite element method (FEM), monitored data, and Peck's formula. It can be indicated that the FEM results agree well with the monitored data at the considered three surface lines (i.e., $Y=15,30$, and $45 \mathrm{~m}$ ), demonstrating the validity of the adopted FEM in investigating the ground deformation characteristics induced by curved twin tunnelling. The Peck's formula predicts a symmetrical distribution of the final ground surface settlement troughs with respect to the plane of $X=50 \mathrm{~m}$, which is seen not to be consistent with the distributions predicted by the FEM and monitored data. The unsymmetrical distributions of the final ground surface settlement troughs result from the unsimultaneous excavations of the side-byside twin tunnels. The advancement of the left tunnel is behind that of the right tunnel with a lagging distance of $36 \mathrm{~m}$. This leads to the occurrence of a second surface settlement above the right tunnel axis when the subsequent excavation is performed. Therefore, as shown in Figure 8, the maximum ground surface settlements above the right tunnel axis are approximately 2 to $3 \mathrm{~mm}$ greater than the ground surface settlements above the left tunnel axis. In addition, a slight ground surface heave less than $1 \mathrm{~mm}$ can be observed on the left-hand side of the left tunnel axis and the righthand side of the right tunnel axis as shown in Figure 8 for the FEM results. This phenomenon does not conform to the monitored results that a slight ground surface settlement occurs within these areas. The reason for this inconformity may be the inherent drawbacks of the adopted soil constitutive models. However, fortunately, as the discrepancy between the ground surface movements obtained by field monitoring and numerical analysis is generally less than $5 \mathrm{~mm}$, which is acceptable in geotechnical engineering, the performance of the adopted FEM in simulating the ground deformation characteristics induced by mechanized shield twin tunnels with curved alignments is satisfactory.

The FEM predicted final ground surface settlement troughs along $Y=30 \mathrm{~m}$ are paralleled in Figure 9 for various radii of curvature of the alignments of the twin curved tunnels. It can be indicated that the effects of the magnitude of the radius of curvature on the shape of surface settlement troughs and on the magnitudes of the surface settlements are trivial. The shape of the surface settlement troughs for the considered radii of curvature resembles the letter of " $w$." The w-shaped surface settlement troughs may be described with the help of three critical points on a surface settlement trough, which are the left bottom, the middle peak, and the right bottom. The left and right bottoms correspond to, respectively, the surface settlements that are directly above the axes of the left and right tunnels, while the middle peak represents the surface settlement that occurred in the position that is equally distant from the two tunnel axes. With a decrease in the magnitude of the radius of curvature from infinity to $50 \mathrm{~m}$, both the bottoms and the middle peaks on the surface settlement troughs move gradually from the righthand side to the left-hand side. This movement remains mild until reaching a radius of curvature of $100 \mathrm{~m}$; however, it becomes drastic when decreasing the magnitude of radius of curvature from 100 to $50 \mathrm{~m}$. At the considered magnitudes of radius of curvature, the magnitudes of the surface settlements range approximately between 7 and $8 \mathrm{~mm}$ for the left bottoms of the $\mathrm{w}$-shaped surface settlement troughs, approximately between 2 and $3 \mathrm{~mm}$ for the middle peaks of the $\mathrm{w}$-shaped surface settlement troughs, and approximately between 8 and $9 \mathrm{~mm}$ for the right bottoms of the w-shaped surface settlement troughs.

The distributions of the final ground surface settlements along $X=41,50$, and $59 \mathrm{~m}$ are compared in Figure 10 for various radii of curvature of tunnel alignments. It can be found that the characteristics of the final ground surface settlement distributions along $X=41 \mathrm{~m}$ [see Figure 10(a)] are similar to that along $X=59 \mathrm{~m}$ [see Figure $10(\mathrm{c})$ ] but differ markedly from the characteristics of the final ground surface settlement distributions along $X=50 \mathrm{~m}$ as depicted in Figure 10(b). Along $X=41$ and $59 \mathrm{~m}$, with increasing $Y$ from 0 to $60 \mathrm{~m}$, the ground surface settlements increase first and then decrease for all the considered radii of curvature. Moreover, a greater radius of curvature corresponds to a greater ground surface settlement over the entire lines of $X=41$ and $59 \mathrm{~m}$. The difference between the ground surface settlements associated with any two magnitudes of radius of curvature is generally smaller than $2 \mathrm{~mm}$ when the magnitudes of radius of curvature are not lower than $150 \mathrm{~m}$. However, when the magnitudes of radius of curvature are no more than $150 \mathrm{~m}$, the difference mentioned above is approximately $4 \mathrm{~mm}$. The ground surface settlement at the starting point of tunnel excavation (i.e., $Y=0 \mathrm{~m}$ ) for the radius of curvature of $50 \mathrm{~m}$ (i.e., $\mathrm{ROC}=50 \mathrm{~m}$ ) can be 


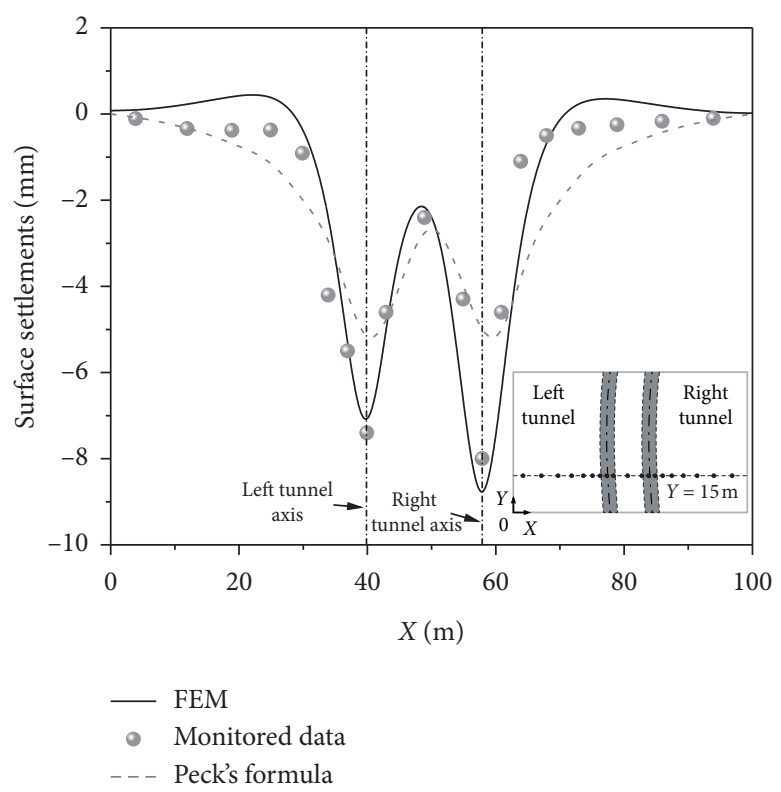

(a)

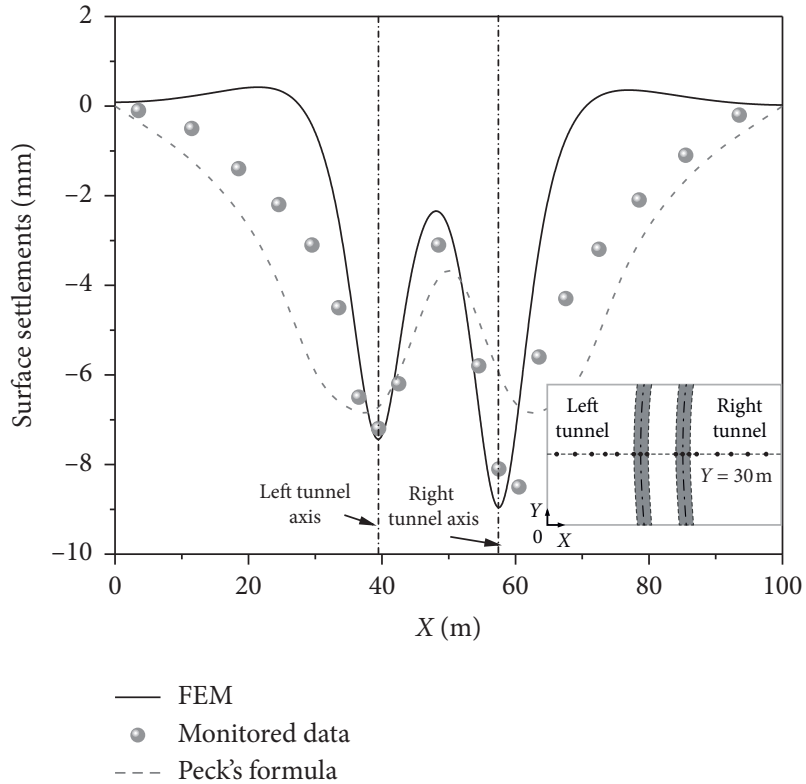

(b)

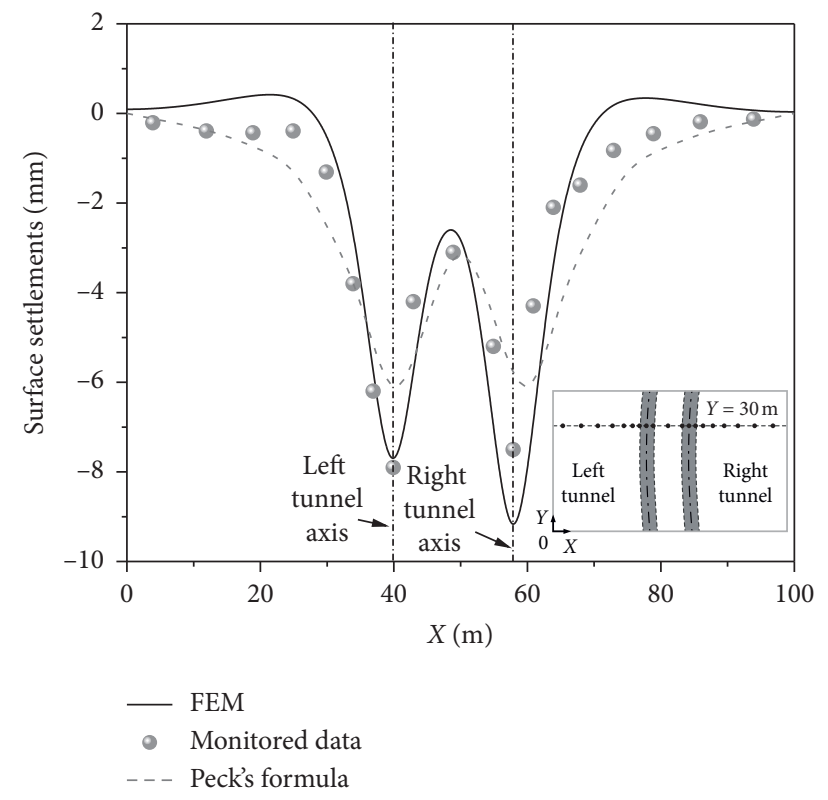

(c)

Figure 8: Ground surface settlement troughs at the final step induced by curved tunnelling of $300 \mathrm{~m}$ in radius of curvature along: (a) $Y=15 \mathrm{~m}$, (b) $Y=30 \mathrm{~m}$, and (c) $Y=45 \mathrm{~m}$.

estimated to be, respectively, $5 \mathrm{~mm}$ along $X=41 \mathrm{~m}$ and $6 \mathrm{~mm}$ along $X=59 \mathrm{~m}$. The ground surface settlements at the starting point of tunnel excavation (i.e., $Y=0 \mathrm{~m}$ ) for the other radii of curvature not including $50 \mathrm{~m}$ are approximately, respectively, $8 \mathrm{~mm}$ along $X=41 \mathrm{~m}$ and $10 \mathrm{~mm}$ along $X=59 \mathrm{~m}$. Contrary to the characteristics of the ground surface settlement distributions along $X=41$ and $59 \mathrm{~m}$, the magnitude of the ground surface settlement increases with a decrease in the radius of curvature from infinity to $50 \mathrm{~m}$. For all the considered radius of curvature, the magnitudes of the ground surface settlements along $X=50 \mathrm{~m}$ are about $3 \mathrm{~mm}$ both at the starting and the ending points of tunnel excavation. At the radius of curvature of $50 \mathrm{~m}$, the ground surface settlement along $X=50 \mathrm{~m}$ peaks within the range of $Y$ between 20 and $40 \mathrm{~m}$ with a magnitude of approximately $9 \mathrm{~mm}$.

4.3. Subsurface Ground Displacements. Figure 11 presents the contours of the final subsurface ground displacements along $Y=30 \mathrm{~m}$ for various radii of curvature considered in this study. It can be indicated that ground settlements occur above the tunnels while ground heaves occur below the tunnels. This trend of ground displacements is attributed to the stress release effect of tunnel excavation. As shown in 


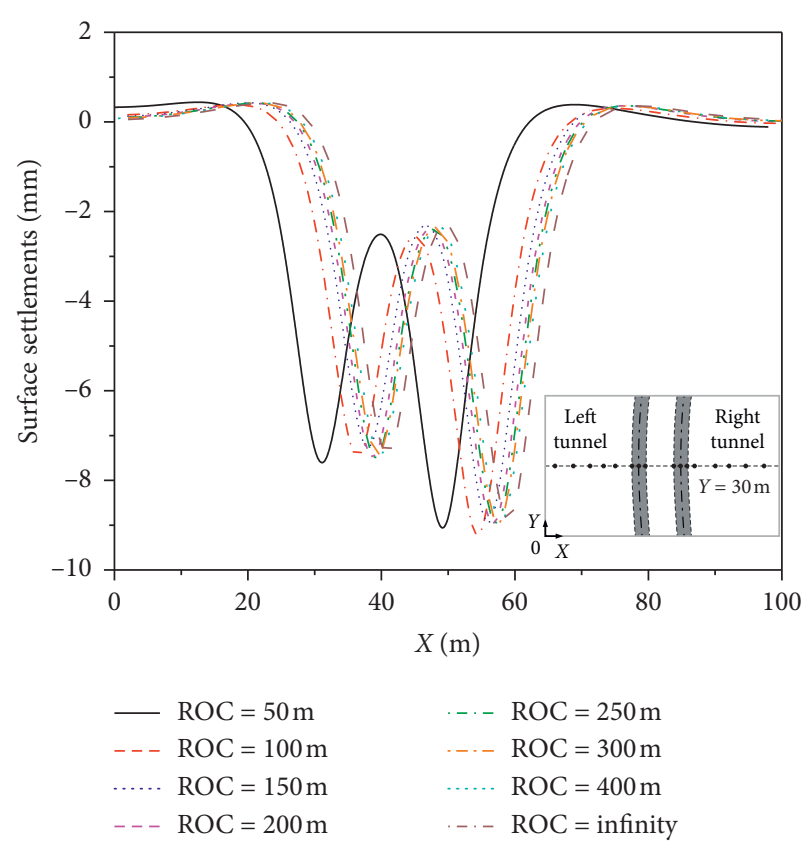

FIGURE 9: Ground surface settlement troughs along $Y=30 \mathrm{~m}$ at the final step induced by curved tunnelling at various radii of curvature.

Figure 11(a), when the radius of curvature of tunnel alignment equals $50 \mathrm{~m}$, the magnitude of the ground settlement decreases from about $9.17 \mathrm{~mm}$ on the ground surface to about $3.08 \mathrm{~mm}$ at the tunnel vault; the ground heaves at the tunnel bottoms are approximately $9.12 \mathrm{~mm}$. Moreover, it is obvious that the widths of the ground settlement troughs vary significantly depending on the cover depth. The width of the settlement trough is roughly two times the diameter of the tunnels on the ground surface, and decreases linearly with increasing the cover depth until reaching the tunnel vault. At the tunnel vault, the width of the settlement trough is nearly the same as the diameter of the tunnels. In addition, a comparison of the contours presented in Figure 11 indicates that an increase in the magnitude of radius of curvature from 50 to $100 \mathrm{~m}$ may lead to a decrease in the width of the settlement trough at the tunnel vault from the same size to the tunnel diameter to half of the tunnel diameter. A slight increase of approximately $2 \mathrm{~mm}$ can be detected in the magnitude of the ground settlement at the tunnel vault when increasing the magnitude of radius of curvature from $50 \mathrm{~m}$ to infinity. The maximum ground heaves along $Y=30 \mathrm{~m}$ induced by tunnelling are, respectively, 9.12, 9.40, 9.55, 9.52, 9.52, 9.50, 9.53, and $9.48 \mathrm{~mm}$ at a radius of curvature of 50, 100, 150, 200, 250, 300, $400 \mathrm{~m}$, and infinity.

The variations of the final horizontal ground displacements along $Y=30 \mathrm{~m}$ with $X$ are presented in Figure 12 for four different depths below ground surface (i.e., $Z=0,-1$, -2 , and $-3 \mathrm{~m})$. It is found that the characteristics of the variations of the final horizontal ground displacements are similar for different depths below ground surface and different radii of curvature of tunnel alignment. These variational curves are characterized by wave shape with two crests (termed as, respectively, the left and the right crests) and two troughs (termed as, respectively, the left and the right troughs). The left crest corresponds to the maximum positive horizontal ground displacement over the entire line of $Y=30 \mathrm{~m}$, while the right crest corresponds to the maximum positive horizontal ground displacement between the two axes of the left and the right tunnels. The left trough corresponds to the maximum negative horizontal ground displacement between the two tunnel axes, while the right trough corresponds to the maximum negative horizontal ground displacement over the entire line of $Y=30 \mathrm{~m}$.

As shown in Figure 12(a), at a radius of curvature, the magnitude of the horizontal ground displacement at the left crest for $Z=0 \mathrm{~m}$ ranges between 4 and $5 \mathrm{~mm}$ according to the magnitude of the radius of curvature of tunnel alignment. A greater horizontal ground displacement at the left crest for $Z=0 \mathrm{~m}$ is achieved at a larger radius of curvature. For the other three cases (i.e., $Z=-1,-2$, and $-3 \mathrm{~m}$ ), the horizontal ground displacement at the left crest decreases slightly with an increase in the cover depth. The left crest is on the left-hand side of the left tunnel axis with a distance of approximately $6 \mathrm{~m}$ between the left crest and the left tunnel axis. The horizontal ground displacement at the right crest for $Z=0 \mathrm{~m}$ ranges between 1.5 and $3 \mathrm{~mm}$ depending on the magnitude of the radius of curvature of tunnel alignment. A difference of roughly $1 \mathrm{~mm}$ can be observed between the horizontal ground displacement at the right crest for $Z=0 \mathrm{~m}$ at the radius of curvature of $50 \mathrm{~m}$ and that at other magnitudes of radius of curvature. The right crest is on the lefthand side of the right tunnel axis with a distance of about $6 \mathrm{~m}$ between the right crest and the right tunnel axis. Similarly, the description of the features of the right crest as well as the horizontal ground displacement at the right crest for the $Z=0 \mathrm{~m}$ case remains a fact for the other three cases as presented in Figure 10(b), 10(c), and 10(d).

For the case of $Z=0 \mathrm{~m}$, the magnitudes of the horizontal ground displacements at the left trough are nearly identical for different radii of curvature except for the radius of curvature of $50 \mathrm{~m}$ [see Figure 12(a)]. They are estimated to be $1 \mathrm{~mm}$, which is $1 \mathrm{~mm}$ lower than the horizontal ground displacement at the left trough for the radius of curvature of $50 \mathrm{~m}$. When compared to the magnitude of the horizontal ground displacement at the left crest for a radius of curvature, it can be noted that the magnitude of the horizontal ground displacement at the left trough equals roughly to one half of the magnitude of the horizontal ground displacement at the left crest. This is because the positive horizontal ground displacement induced by the excavation of the right tunnel has counteracted in part the negative horizontal ground displacement at the left trough induced by the excavation of the left tunnel. For all the considered cases, the magnitudes of the horizontal ground displacements at the right troughs vary from 3 to $6 \mathrm{~mm}$. The maximum horizontal ground displacement at the right trough (i.e., $6 \mathrm{~mm}$ ) is achieved at the radius of curvature of $50 \mathrm{~m}$ for the $Z=0 \mathrm{~m}$ case. For any of the considered cases, it is shown that the horizontal ground displacement at the right trough is generally $1 \mathrm{~mm}$ greater at the radius of curvature of $50 \mathrm{~m}$ than at the other radii of curvature. The right trough is on the 


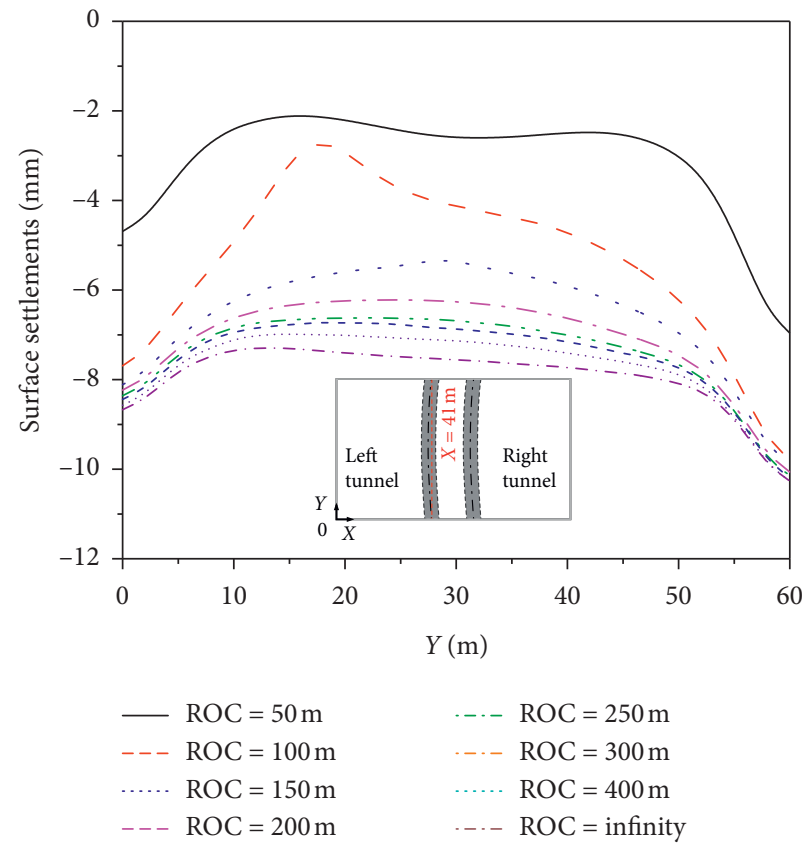

(a)

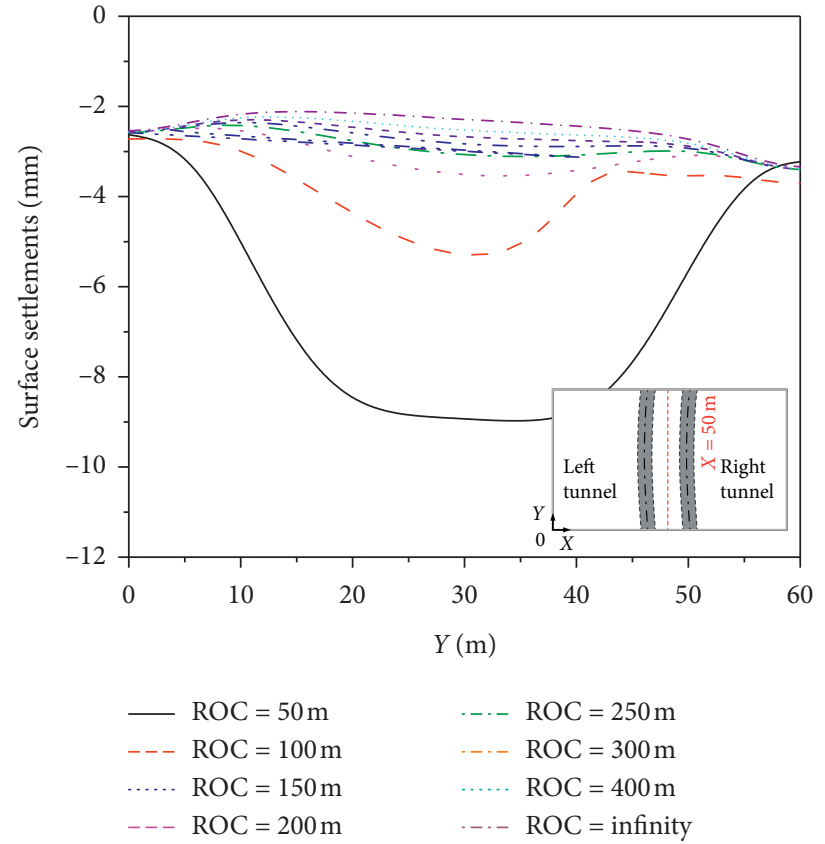

(b)

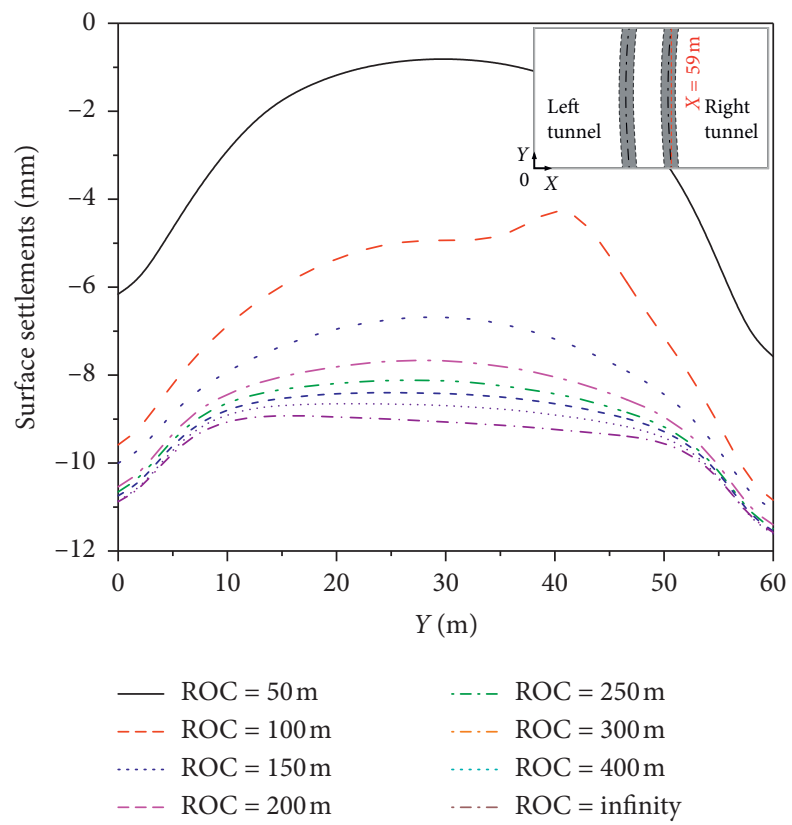

(c)

FIGURE 10: Distributions of ground surface settlements at the final step induced by curved tunnelling at various radii of curvature along: (a) $X=41 \mathrm{~m}$, (b) $X=50 \mathrm{~m}$, and (c) $X=59 \mathrm{~m}$.

right-hand side of the right tunnel axis with a distance of approximately $6 \mathrm{~m}$ between the right trough and the right tunnel axis.

4.4. Discussion. The numerical analysis results presented above indicate that a reduction in the radius of curvature of tunnel alignment from infinity has a beneficial effect on the restraining of the tunnelling-induced ground displacements above the axis of the tunnel with a radius of curvature of infinity (i.e., straight-line tunnels). However, many construction issues associated with tunnelling along the curved alignment of small radius of curvature are more practically attractive for geotechnical engineering practitioners. Therefore, a discussion of the measures for ensuring the stability and construction disturbance minimization of curved tunnelling with a small radius of curvature is made herein for the benefit of the engineers that are interested in this topic.

The control of the tunnelling direction and the installation of the tunnel lining segments are the two major 


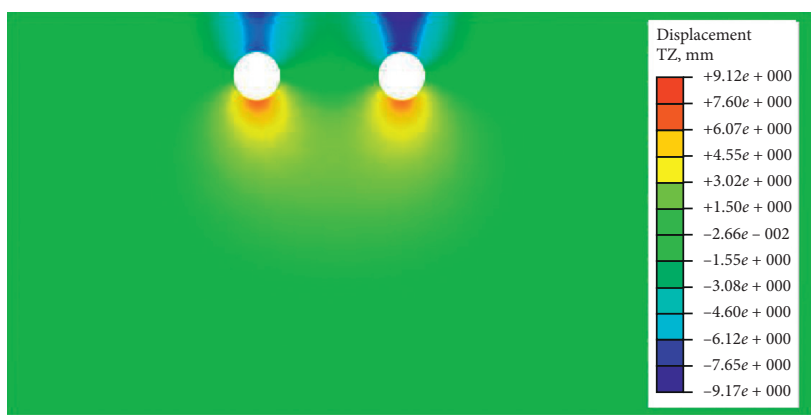

(a)

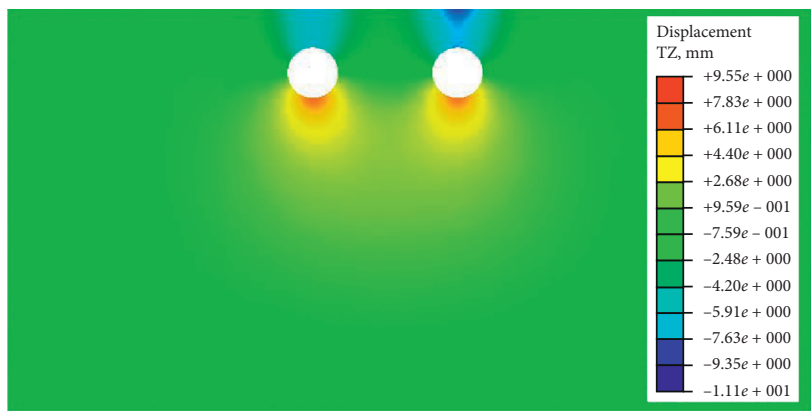

(c)

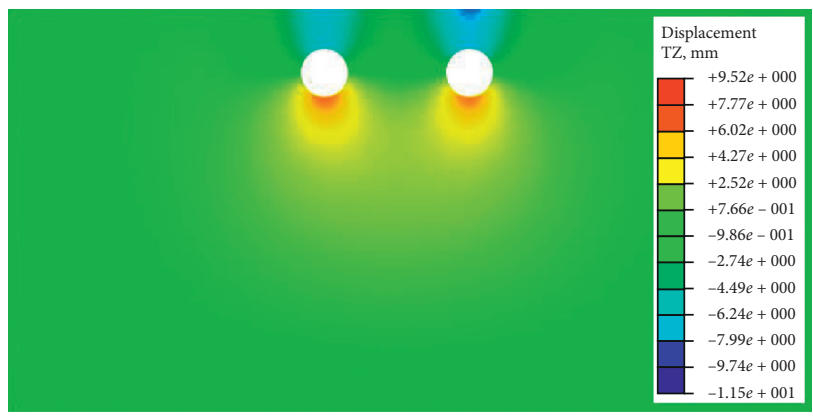

(e)

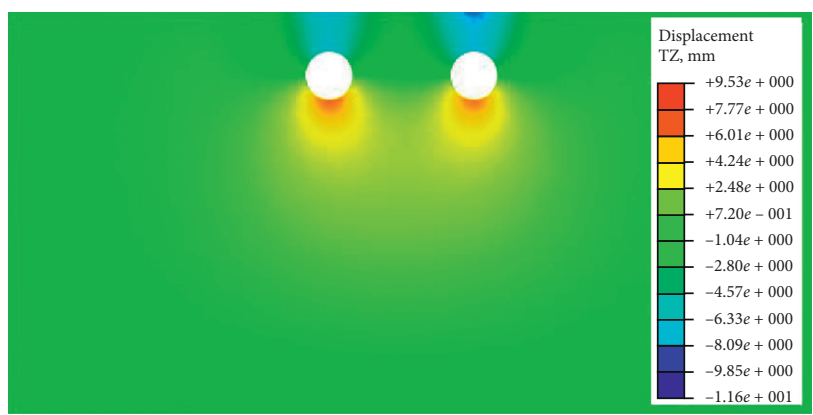

(g)

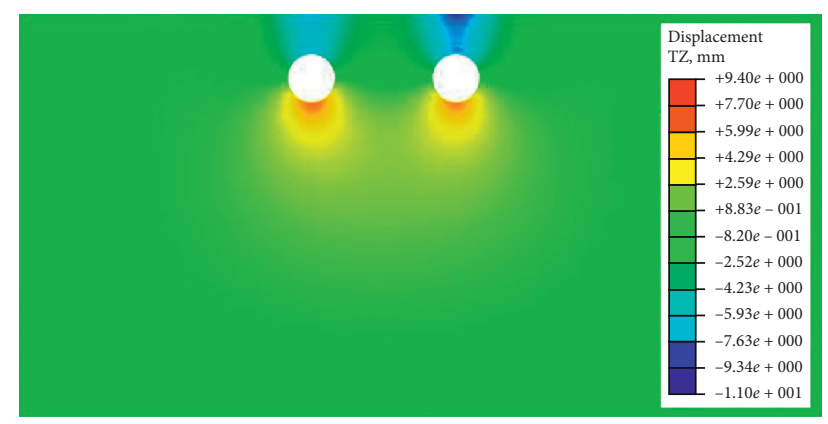

(b)

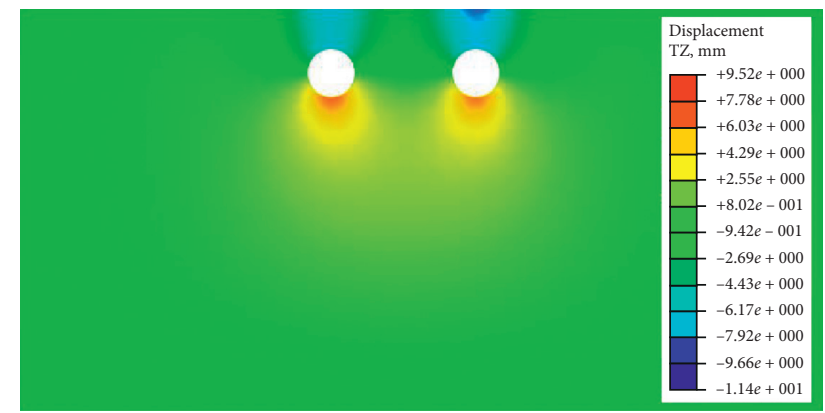

(d)

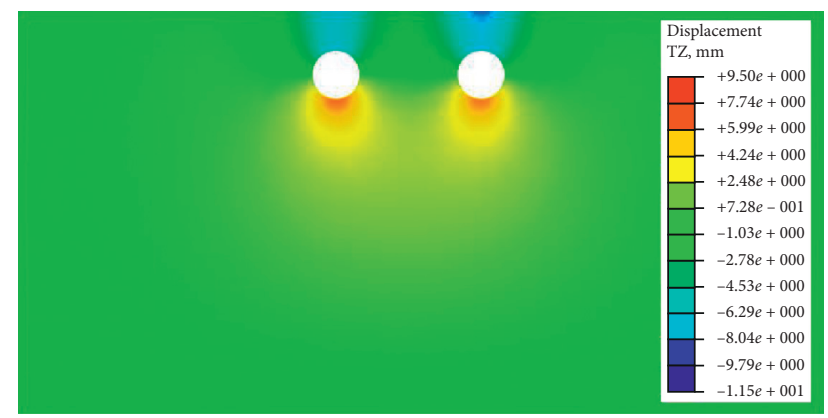

(f)

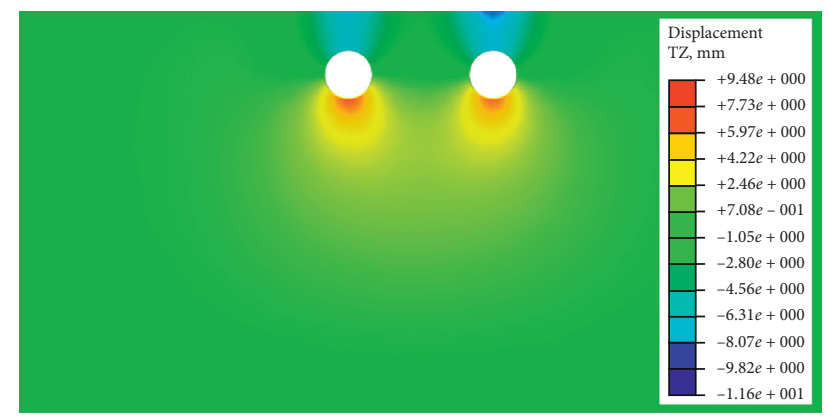

(h)

Figure 11: Contours of subsurface vertical ground displacements at the final step along $Y=30 \mathrm{~m}$ induced by curved tunnelling at various radii of curvature: (a) $50 \mathrm{~m}$, (b) $100 \mathrm{~m}$, (c) $150 \mathrm{~m}$, (d) $200 \mathrm{~m}$, (e) $250 \mathrm{~m}$, (f) $300 \mathrm{~m}$ (g) $400 \mathrm{~m}$, and (h) infinity.

difficulties encountered during curved tunnelling with a small radius of curvature. As the tunnelling boring machine (TBM) is not curved in shape, the entire driving path of TBM for a curved tunnel actually consists of a series of extremely short straight-line paths. These straight-line paths are tangentially related to the predetermined curved alignment of the tunnel, indicating that a constant adjustment of the TBM posture is required during the entire tunnelling process. A good adjustment of the TBM posture is difficult, and therefore a certain overexcavation is inevitably induced, which has an important effect on the ground loss. The ground loss and the subsequent ground surface settlement will be exacerbated if the grouting is not timely or the grout amount is not sufficient. Moreover, if the grout amount on the external side of the curved tunnel alignment is not sufficient, a certain horizontal offset of the tunnel toward the 

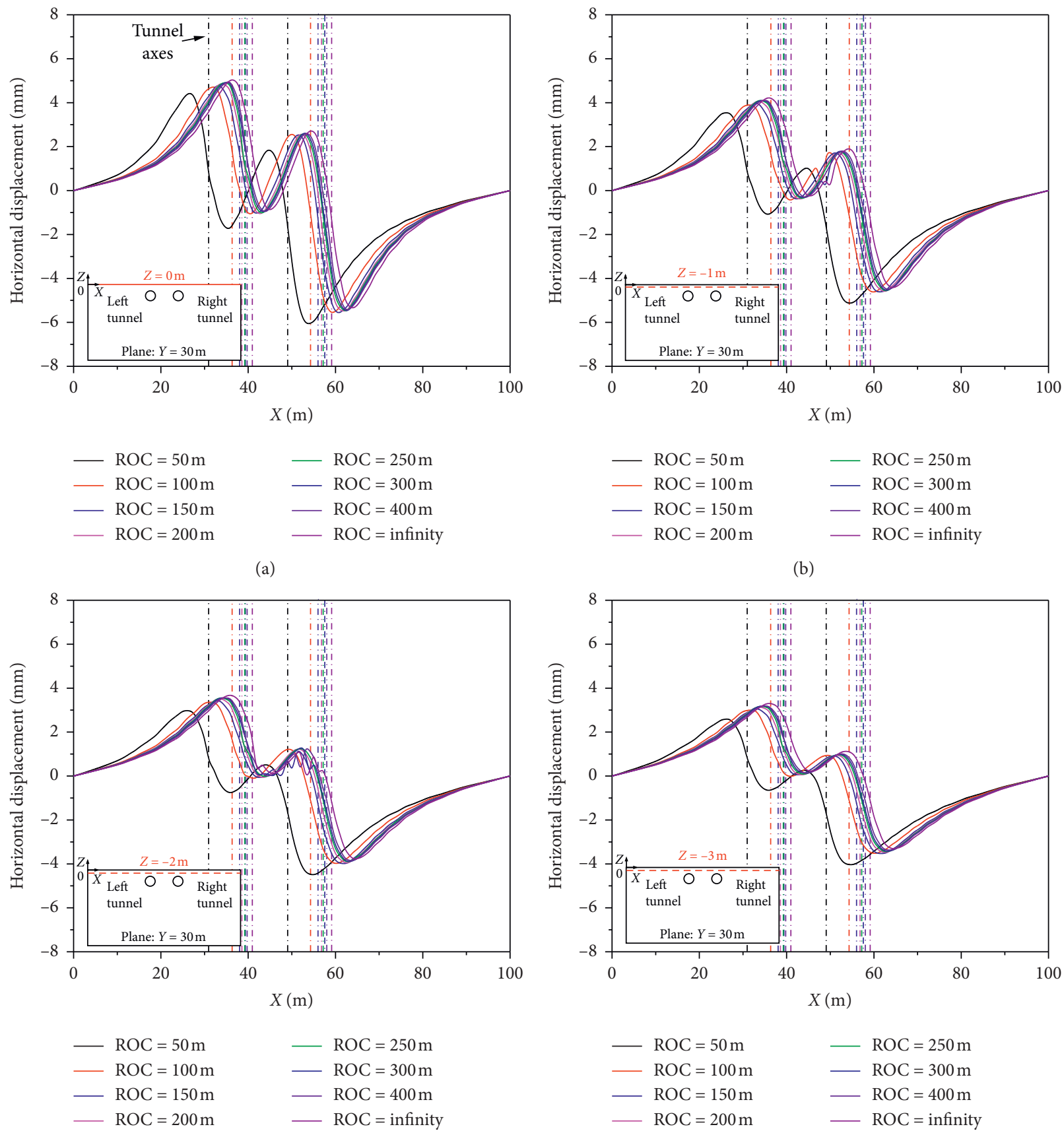

(c)

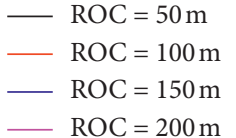

ROC $=200 \mathrm{~m}$

Figure 12: Tunnelling induced horizontal ground displacements at the final step along $Y=30 \mathrm{~m}$ at different depths: (a) $Z=0 \mathrm{~m}$, (b) $Z=-1 \mathrm{~m}$, (c) $Z=-2 \mathrm{~m}$, and (d) $Z=-3 \mathrm{~m}$.

external side of the curved tunnel alignment may be produced due to the action of the counter-force of the tunnel excavation force. To tackle this problem, an advance offset procedure as depicted in Figure 13 can be carried out. In this procedure, the adopted curved alignment of tunnel is obtained by offsetting the designed curved alignment of tunnel toward the internal side at an appropriate distance. Generally, the magnitude of the advance offset distance ranges between 20 and $40 \mathrm{~mm}$, depending on many factors such as geological conditions and radius of curvature of tunnel alignment. A smaller radius of curvature corresponds to a greater advance offset distance. In addition, a slight adjustment of the advance offset distance may be required taking account of the monitored tunnel offset during construction.

The installation of the tunnel lining segments for a curved tunnel with a small radius of curvature of alignment needs to be carefully performed to achieve an accurate curve fitting of the tunnel alignment. To facilitate this installation process, the universal wedge-shaped (UWS) segments are frequently adopted. It's much better to adopt a UWS segment with as much as large wedge quantity. The wedge 


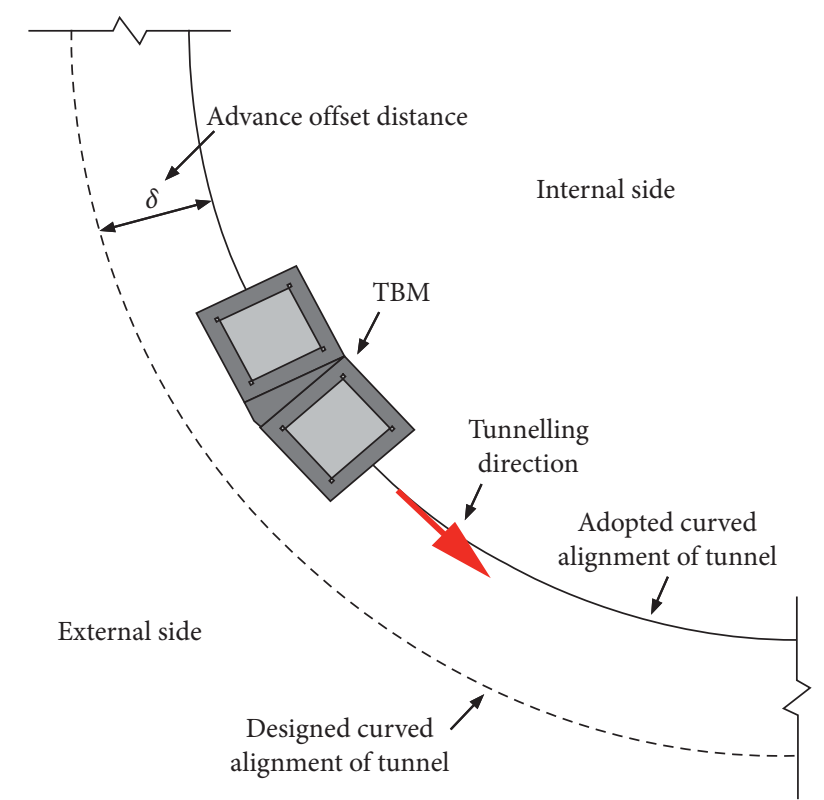

FIGURE 13: Schematic diagram of advance offset for tunnel alignment.

quantity depends on many factors such as segment type, segment width, external diameter of segment, radius of curvature of tunnel alignment, use ratio of wedge ring, and reinforcement ratio of the segment. In addition, a smaller width of tunnel lining segments is more beneficial for curve fitting of tunnel alignment, installation of tunnel lining segments, reduction in segment fragmentation, and improvement in tunnel waterproofing ability.

\section{Conclusions}

The ground deformation characteristics induced by mechanized shield twin tunnelling along curved alignments with various radii of curvature are investigated in this study. A typical case history of curved twin tunnelling in plastic clays is reported. Nonlinear three-dimensional (3D) finite element method (FEM) is used to simulate the tunnelling process and to analyze the tunnelling-induced ground displacements. A good agreement among the numerical analysis results, the field monitoring data, and the predicted results by the empirical Gaussian formula verifies the good performance of the adopted nonlinear 3D FEM. A discussion of the critical construction technologies for the curved shield tunnel with a small radius of curvature is also presented. The conclusions drawn from this study can be summarized as follows:

(i) A superposition of the Peck's empirical Gaussian formula for single straight-line tunnel is applicable for the preliminary estimation of the ground surface settlements induced by curved twin tunnelling. The inability of the superimposed Peck's empirical Gaussian formula in capturing the unsymmetrical distribution of the transverse ground surface settlements is trivial if the distance between the two tunnel axes is large enough or the distance between the tunnel faces is sufficiently small. (ii) The difference between the ground surface settlements associated with any two magnitudes of radius of curvature is generally smaller than $2 \mathrm{~mm}$ when the magnitudes of radius of curvature are not lower than $150 \mathrm{~m}$. However, when the magnitudes of radius of curvature are no more than $150 \mathrm{~m}$, the difference mentioned above is approximately $4 \mathrm{~mm}$.

(iii) An increase in the magnitude of radius of curvature from 50 to $100 \mathrm{~m}$ may lead to a decrease in the width of the settlement trough at the tunnel vault from the same size to the tunnel diameter to half of the tunnel diameter. The variations of the final horizontal ground displacements are wave shaped for different depths below ground surface and different radii of curvature of tunnel alignment.

(iv) The advance offset procedure is beneficial for the mitigation of the overexcavation resulting from a constant adjustment of TBM posture during tunnelling. An appropriate magnitude of the advance offset distance ranges between 20 and $40 \mathrm{~mm}$, depending on geological conditions and the radius of curvature of tunnel alignment. The use of universal wedge-shaped segments, smaller in segment width and larger in wedge quantity, facilitates the installation of tunnel lining segments for curved tunnels with small radius of curvature.

\section{Data Availability}

The data used to support the findings of this study are available from the corresponding author upon request.

\section{Conflicts of Interest}

The authors declare that there are no conflicts of interest.

\section{Acknowledgments}

This work was supported by the National Natural Science Foundation of China (grant numbers 51778575 and 42077249).

\section{References}

[1] X. Yu, J. Cheng, C. Cao, E. Li, and J. Feng, "Probabilistic analysis of tunnel liner performance using random field theory," Advances in Civil Engineering, vol. 2019, Article ID 1348767, 18 pages, 2019.

[2] Y. X. Wang, S. B. Shan, C. Zhang, and P. P. Guo, "Seismic response of tunnel lining structure in a thick expansive soil stratum," Tunnelling and Underground Space Technology, vol. 88, pp. 250-259, 2019.

[3] C. He and B. Wang, "Research progress and development trends of highway tunnels in China," Journal of Modern Transportation, vol. 21, no. 4, pp. 209-223, 2013.

[4] A. Franza, S. Ritter, and M. J. Dejong, "Continuum solutions for tunnel-building interaction and a modified framework for deformation prediction," Géotechnique, vol. 70, no. 2, pp. 108-122, 2020

[5] J. Li, Y. Fang, C. Liu, Y. Zhang, and W. Lu, "Performance investigation of tunnel lining with cavities around 
surrounding rocks," Advances in Civil Engineering, vol. 2020, Article ID 1364984, 5 pages, 2020.

[6] Y.-Q. Wang, W.-K. Kong, and Z.-F. Wang, "Effect of expanding a rectangular tunnel on adjacent structures," Advances in Civil Engineering, vol. 2018, Article ID 1729041, 13 pages, 2018.

[7] E. Pujades, J. Carrera, E. Vázquez-Suñé, A. Jurado, V. Vilarrasa, and E. Mascuñano-Salvador, "Hydraulic characterization of diaphragm walls for cut and cover tunnelling," Engineering Geology, vol. 125, pp. 1-10, 2012.

[8] T. O. L. Roberts, H. Roscoe, W. Powrie, and D. J. E. Butcher, "Controlling clay pore pressures for cut-and-cover tunnelling," Proceedings of the Institution of Civil Engineers-Geotechnical Engineering, vol. 160, no. 4, pp. 227-236, 2007.

[9] H. Yang, X. Jiang, and P. Lian, "Seismic response of tunnel lining for shallow-bias tunnel with a small clear distance under Wenchuan earthquake," Advances in Civil Engineering, vol. 2018, Article ID 2578062, 10 pages, 2018.

[10] L. Huang, R. A. Bohne, A. Bruland, P. D. Jakobsen, and J. Lohne, "Environmental impact of drill and blast tunnelling: life cycle assessment," Journal of Cleaner Production, vol. 86, pp. 110-117, 2015.

[11] Y. Xue and Y. Li, "A fast detection method via region-based fully convolutional neural networks for shield tunnel lining defects," Computer-Aided Civil and Infrastructure Engineering, vol. 33, no. 8, pp. 638-654, 2018.

[12] T. Zhao, W. Liu, and Z. Ye, "Effects of water inrush from tunnel excavation face on the deformation and mechanical performance of shield tunnel segment joints," Advances in Civil Engineering, vol. 2017, Article ID 5913640, 18 pages, 2017.

[13] E. B. Aygar, "Evaluation of new Austrian tunnelling method applied to Bolu tunnel's weak rocks," Journal of Rock Mechanics and Geotechnical Engineering, vol. 12, no. 3, pp. 541-556, 2020.

[14] G. M. Ji, T. Kanstad, and $\varnothing$. Bjøntegaard, "Crack risk evaluation of submerged concrete tunnel during hardening phase," Advances in Civil Engineering, vol. 2018, Article ID 7354025, 14 pages, 2018.

[15] Z. Wang, Z. Hu, J. Lai, H. Wang, K. Wang, and W. Zan, "Settlement characteristics of jacked box tunneling underneath a highway embankment," Journal of Performance of Constructed Facilities, vol. 33, no. 2, Article ID 04019005, 2019.

[16] Z. Mi, L. Chen, L. Pan, J. Chen, and R. Wu, "An electrohydraulic system for synchronously jacked box tunneling in shallow saturated soft soil cover," Automation in Construction, vol. 25, pp. 1-7, 2012.

[17] M. Nematollahi and D. Dias, "Interaction between an underground parking and twin tunnels-case of the Shiraz subway line," Tunnelling and Underground Space Technology, vol. 95, Article ID 103150, 2020.

[18] X. Chen, X. Li, and H. Zhu, "Condition evaluation of urban metro shield tunnels in Shanghai through multiple indicators multiple causes model combined with multiple regression method," Tunnelling and Underground Space Technology, vol. 85, pp. 170-181, 2019.

[19] Z.-G. Yan, H.-H. Zhu, J. Woody Ju, and W.-Q. Ding, "Fullscale fire tests of RC metro shield TBM tunnel linings," Construction and Building Materials, vol. 36, pp. 484-494, 2012.

[20] F. Huang, M. Zhang, F. Wang, T. Ling, and X. Yang, "The failure mechanism of surrounding rock around an existing shield tunnel induced by an adjacent excavation," Computers and Geotechnics, vol. 117, Article ID 103236, 2020.

[21] S. He, J. Lai, L. Wang, and K. Wang, "A literature review on properties and applications of grouts for shield tunnel," Construction and Building Materials, vol. 239, Article ID 117782, 2020.

[22] J. Chen, Z. Xu, Y. Luo, J. Song, W. Liu, and F. Dong, “Application of the upper-bench CD method in super large-span and shallow tunnel: a case study of Letuan tunnel," Advances in Civil Engineering, vol. 2020, Article ID 8826232, 16 pages, 2020.

[23] B. Yuan, M. Sun, L. Xiong, Q. Luo, S. P. Pradhan, and H. Li, "Investigation of 3D deformation of transparent soil around a laterally loaded pile based on a hydraulic gradient model test," Journal of Building Engineering, vol. 28, no. 3, Article ID 101024, 2020.

[24] B. X. Yuan, M. Sun, Y. X. Wang, L. H. Zhai, and Q. Z. Luo, "Full 3D displacement measuring system for 3D displacement field of soil around a laterally loaded pile in transparent soil," International Journal of Geomechanics, vol. 19, no. 5, Article ID 04019028, 2019.

[25] R. J. Finno and G. W. Clough, "Evaluation of soil response to EPB shield tunneling," Journal of Geotechnical Engineering, vol. 111, no. 2, pp. 155-173, 1985.

[26] S. Bernat, B. Cambou, and P. Dubois, "Assessing a soft soil tunnelling numerical model using field data," Géotechnique, vol. 49, no. 4, pp. 427-452, 1999.

[27] S. Bernat and B. Cambou, "Soil-structure interaction in shield tunnelling in soft soil," Computers and Geotechnics, vol. 22, no. 3-4, pp. 221-242, 1998.

[28] G. W. Clough, B. P. Sweeney, and R. J. Finno, "Measured soil response to EPB shield tunneling," Journal of Geotechnical Engineering, vol. 109, no. 2, pp. 131-149, 1983.

[29] Y. Luo, J. Chen, Z. Shi, S. Zhang, W. Liu, and Y. Li, "Mechanical and deformation characteristics and optimization of support parameters for superlarge-span tunnel: a case study from Laohushan tunnel," Advances in Civil Engineering, vol. 2020, Article ID 8882019, 17 pages, 2020.

[30] C. Liu, Z. Peng, L. Pan et al., "Influence of tunnel boring machine (TBM) advance on adjacent tunnel during ultrarapid underground pass (URUP) tunneling: a case study and numerical investigation," Applied Sciences, vol. 10, no. 11, p. 3746, 2020.

[31] N.-A. Do, D. Dias, P. Oreste, and I. Djeran-Maigre, "Threedimensional numerical simulation for mechanized tunnelling in soft ground: the influence of the joint pattern," Acta Geotechnica, vol. 9, no. 4, pp. 673-694, 2014.

[32] M. Nematollahi and D. Dias, "Three-dimensional numerical simulation of pile-twin tunnels interaction-case of the Shiraz subway line," Tunnelling and Underground Space Technology, vol. 86, pp. 75-88, 2019.

[33] N.-A. Do, D. Dias, P. Oreste, and I. Djeran-Maigre, "Threedimensional numerical simulation of a mechanized twin tunnels in soft ground," Tunnelling and Underground Space Technology, vol. 42, pp. 40-51, 2014.

[34] H.-N. Wu, S.-L. Shen, R.-P. Chen, and A. Zhou, "Three-dimensional numerical modelling on localised leakage in segmental lining of shield tunnels," Computers and Geotechnics, vol. 122, Article ID 103549, 2020.

[35] G. Swoboda and A. Abu-Krisha, "Three-dimensional numerical modelling for TBM tunnelling in consolidated clay," Tunnelling and Underground Space Technology, vol. 14, no. 3, pp. 327-333, 1999. 
[36] Z.-r. Huang, W. Zhu, J.-h. Liang, J. Lin, and R. Jia, “Threedimensional numerical modelling of shield tunnel lining," Tunnelling and Underground Space Technology, vol. 21, no. 34, p. 434, 2006.

[37] A. Alsahly, J. Stascheit, and G. Meschke, "Advanced finite element modeling of excavation and advancement processes in mechanized tunneling," Advances in Engineering Software, vol. 100, pp. 198-214, 2016.

[38] X. Xie and G. Tang, "Effects of curved shield tunnelling adjacent to existing power tunnel," European Journal of Environmental and Civil Engineering, vol. 22, no. sup1, pp. 164-178, 2018.

[39] M. Zhang, S. Li, and P. Li, "Numerical analysis of ground displacement and segmental stress and influence of yaw excavation loadings for a curved shield tunnel," Computers and Geotechnics, vol. 118, Article ID 103325, 2020.

[40] M. Sugimoto, A. Sramoon, S. Konishi, and Y. Sato, "Simulation of shield tunneling behavior along a curved alignment in a multilayered ground," Journal of Geotechnical and Geoenvironmental Engineering, vol. 133, no. 6, pp. 684-694, 2007.

[41] J. Niu, X. Jiang, and F. Wang, "Stability analysis of rock slope with small spacing tunnel under earthquakes and influence of ground motion parameters," Geotechnical and Geological Engineering, vol. 36, no. 4, pp. 2437-2453, 2018.

[42] L. Duris and E. Hrubesova, "Numerical simulation of the interaction between fibre concrete slab and subsoil-the impact of selected determining factors," Sustainability, vol. 12, no. 23, 10 pages, Article ID 10036, 2020.

[43] B. X. Yuan, L. Xiong, L. Zhai et al., "Transparent synthetic soil and its application in modeling of soil-structure interaction using optical system," Frontiers in Earth Science, vol. 7, p. 276, 2019.

[44] P. Guo, X. Gong, and Y. Wang, "Displacement and force analyses of braced structure of deep excavation considering unsymmetrical surcharge effect," Computers and Geotechnics, vol. 113, Article ID 103102, 2019.

[45] S. Yu and Y. Geng, "Influence analysis of underground excavation on the adjacent buildings and surrounding soil based on scale model test," Advances in Civil Engineering, vol. 2019, Article ID 6527175, 15 pages, 2019.

[46] M.-G. Li, X. Xiao, J.-H. Wang, and J.-J. Chen, "Numerical study on responses of an existing metro line to staged deep excavations," Tunnelling and Underground Space Technology, vol. 85, pp. 268-281, 2019.

[47] Y.-Q. Zhang, J.-H. Wang, and M.-G. Li, "Effect of dewatering in a confined aquifer on ground settlement in deep excavations," International Journal of Geomechanics, vol. 18, no. 10, Article ID 04018120, 2018.

[48] Y.-Q. Zhang, J.-H. Wang, J.-J. Chen, and M.-G. Li, "Numerical study on the responses of groundwater and strata to pumping and recharge in a deep confined aquifer," Journal of Hydrology, vol. 548, pp. 342-352, 2017.

[49] F. Wang, Q. Ren, P. Zou et al., "Acceleration and displacement dynamic response laws of a shallow-buried bifurcated tunnel," Journal of Vibroengineering, vol. 21, no. 4, pp. 1015-1029, 2019.

[50] Y. Wang, Z. Li, H. Jing, Y. Li, and M. Wang, "Study on the seepage characteristics of deep buried tunnels under variable high-pressure water heads," Bulletin of Engineering Geology and the Environment, vol. 80, pp. 1477-1487, 2021.

[51] R. B. Peck, "Deep excavation and tunneling in soft ground," in Proceedings of the 7th International Conference on Soil
Mechanics and Foundation Engineering, pp. 225-290, Mexico City, Mexico, September 1969.

[52] N. Loganathan and H. G. Poulos, "Analytical prediction for tunneling-induced ground movements in clays," Journal of Geotechnical and Geoenvironmental Engineering, vol. 124, no. 9, pp. 846-856, 1998.

[53] J. R. Standing and D. Selemetas, "Greenfield ground response to EPBM tunnelling in London clay," Géotechnique, vol. 63, no. 12, pp. 989-1007, 2013.

[54] X. Xie, Y. Yang, and M. Ji, "Analysis of ground surface settlement induced by the construction of a large-diameter shield-driven tunnel in Shanghai, China," Tunnelling and Underground Space Technology, vol. 51, pp. 120-132, 2016.

[55] D.-J. Ren, S.-L. Shen, A. Arulrajah, and H.-N. Wu, "Evaluation of ground loss ratio with moving trajectories induced in double-O-tube (DOT) tunnelling," Canadian Geotechnical Journal, vol. 55, no. 6, pp. 894-902, 2018.

[56] X. Liu, Q. Fang, D. Zhang, and Y. Liu, "Energy-based prediction of volume loss ratio and plastic zone dimension of shallow tunnelling," Computers and Geotechnics, vol. 118, Article ID 103343, 2020.

[57] S. Knothe, "Observations of surface movements under influence of mining and their theoretical interpretation," in Proceedings of European Conference on Ground Movement, pp. 210-218, Berlin, Germany, February 1957.

[58] P. B. Attewell and I. W. Farmer, "Ground deformations resulting from shield tunnelling in London clay," Canadian Geotechnical Journal, vol. 11, no. 3, pp. 380-395, 1974.

[59] G. W. Clough and B. Schmidt, "Chapter 8-design and performance of Excavations and tunnels in soft clay," Developments in Geotechnical Engineering, vol. 20, pp. 567-634, 1981.

[60] J. H. Atkinson and D. M. Potts, "Subsidence above shallow tunnels in soft ground," Journal of Geotechnical and Geoenvironmental Engineering, vol. 103, no. GT4, pp. 307-325, 1977.

[61] W. J. Rankin, "Ground movements resulting from urban tunnelling: predictions and effects," Geological Society, London, Engineering Geology Special Publications, vol. 5, no. 1, pp. 79-92, 1988.

[62] M. P. O’Reilly and B. M. New, "Settlement above tunnels in the United Kingdom-their magnitude and prediction," in Proceedings of the Tunnelling 82 third International Symposium, pp. 173-181, Institution of Mining and Metallurgy, London, England, June 1982.

[63] S.-L. Chen, M.-W. Gui, and M.-C. Yang, "Applicability of the principle of superposition in estimating ground surface settlement of twin-and quadruple-tube tunnels," Tunnelling and Underground Space Technology, vol. 28, pp. 135-149, 2012. 